\title{
Synthesis of Multi-Protein Complexes through Charge-Directed Sequential Activation of Tyrosine Residues
}

Casey Mogilevsky, ${ }^{\dagger, \ddagger}$ Marco J. Lobba, ${ }^{\dagger, \ddagger}$ Daniel Brauer, ${ }^{\ddagger}$ Alan M. Marmelstein, ${ }^{\ddagger}$ Johnathan C. Maza, ${ }^{\ddagger}$ Jamie M. Gleason, ${ }^{\ddagger}$ Jennifer A. Doudna, ${ }^{\ddagger}, \boldsymbol{\Phi}, \S, \|, \perp$ and

1 \author{
Matthew B. Francis*, ${ }^{*, \#}$ \\ $\dagger$ These authors contributed equally \\ $\ddagger$ Department of Chemistry, University of California, Berkeley \\ IDepartment of Molecular and Cell Biology, University of California, Berkeley \\ $\S$ Gladstone Institutes, San Francisco \\ || Howard Hughes Medical Institute, University of California, Berkeley \\ $\perp$ Innovative Genomics Institute, University of California, Berkeley \\ \#Materials Sciences Division, Lawrence Berkeley National Laboratories, Berkeley \\ E-mail: mbfrancis@berkeley.edu
}

\begin{abstract}
Site-selective protein-protein coupling has long been a goal of chemical biology research. In recent years, that goal has been realized to varying degrees through a number of techniques, including the use of tyrosinase-based coupling strategies. Early publications utilizing tyrosinase from Agaricus bisporus showed the potential to convert tyrosine residues into ortho-quinone functional groups, but this enzyme is challenging to produce recombinantly and suffers from some limitations in substrate scope.
\end{abstract}


Initial screens of several tyrosinase candidates revealed that the tyrosinase from Bacillus megaterium (megaTYR) as an enzyme that possesses a broad substrate tolerance. We use the expanded substrate preference as a starting point for protein design experiments and show that single point mutants of megaTYR are capable of activating tyrosine residues in various sequence contexts. We leverage this new tool to enable the construction of protein trimers via a charge-directed sequential activation of tyrosine residues (CDSAT).

\section{Introduction}

Site-selective post-translational modification of proteins has long been an object of study for both chemists and biologists. Augmenting the native properties of protein scaffolds to contain fluorophores, ${ }^{1,2}$ drug molecules ${ }^{3}$ and other signalling moieties has been of tremendous value to both our understanding biology and the creation of new therapeutics. ${ }^{3-6}$ While much work has been done in the attachment of small molecule cargoes to protein scaffolds, the facile attachment of additional whole proteins has proven more difficult. The primary challenge of protein-protein coupling lies in the steric inhibition that must be overcome in joining large molecules, as well as the difficulty in generating suitable selective reaction handles due to the frequent occurrence of most native amino acids. Current methods for the site-selective synthesis of protein conjugates involve the introduction of uniquely reactive unnatural amino acids (UAAs) into the backbone sequence, ${ }^{7,8}$ maleimide-cysteine linkages, ${ }^{9}$ and enzymatic coupling reactions. ${ }^{6,10-13}$

Although these methods have addressed many important challenges in chemical biology, limitations still exist. The site selective incorporation of unnatural amino acids into proteins relies on stop codon repurposing, which requires special growth media and often lowers protein yield. ${ }^{7,8}$ Thiol-reactive crosslinkers, such as maleimides, are specific to cysteine residues on the protein surface that are rare enough to afford selectivity and can be readily inserted via single base mutagenesis. However, the maleimide reactive handle is challenging to install 
on the surface of full proteins. ${ }^{9}$ For many enzymatic coupling techniques, such as sortase, butelase, and farnesyltransferase, coupling can only occur at the N- and C- termini. ${ }^{6,10-13}$ Most other coupling approaches such as SpyCatcher/SpyTag require the insertion of bulky recognition domains. ${ }^{14}$

A promising alternative is tyrosinase, a broadly distributed class of enzymes involved in the melanin synthesis pathway in every kingdom of life. Tyrosinase enzymes normally catalyze the oxidation of tyrosine to a dopaquinone intermediate, which then cyclizes to form dopachrome. ${ }^{15-19}$ Recent studies have repurposed the commercially available mushroom tyrosinase (abTYR) to catalyze site specific oxidative coupling reactions at N- and Cterminal tyrosine residues using different types of coupling partners: strained alkynes, ${ }^{20}$ and nucleophilic coupling partners such as secondary amines, ${ }^{21}$ anilines, ${ }^{22}$ and surface exposed cysteine residues, ${ }^{23}$ which expands the possible sites of enzymatic protein-protein bioconjugation past the N- and C- termini. This methodology is versatile, and can take place at temperatures ranging from $4{ }^{\circ} \mathrm{C}$ to room temperature and near-neutral $\mathrm{pH}$, to preserve the function of sensitive proteins. ${ }^{23}$

Despite the recent success and convenience of abTYR, it is not without limitations. In a recent investigation, abTYR was unable to activate tyrosine residues at the $\mathrm{C}$ terminus of protein L, regardless of linker length. ${ }^{22}$ Both abTYR and protein L are over $100 \mathrm{kDa}$ in mass, and are negatively charged, suggesting that electrostatic repulsion and steric hinderance may be the factors preventing the activation of this particular substrate by abTYR. ${ }^{24,25} \mathrm{~A}$ smaller, $35.5 \mathrm{kDa}$ tyrosinase from Bacillus megaterium (megaTYR, referred to as bmTYR in ref 17), ${ }^{17}$ was found to activate C-terminal tyrosines on protein L regardless of linker length. In this study we characterize the substrate preferences of these tyrosinases, and show that abTYR is unable to oxidize tyrosines in negatively charged substrates, whereas megaTYR, and the recently reported tyrosinase from the archaeon, Candidatus Nitrosopumilus koreensis (cnkTYR) ${ }^{26}$ are much more promiscuous. In this report, we use this information to generate new versions of megaTYR selective for tyrosine residues in specific charge contexts. Moreover, 
we leverage this new tool to enable the construction of protein trimers via charge-directed sequential activation of tyrosine residues (CDSAT).

\section{Results and discussion}

In our search for more sequence permissive enzymes we identified tyrosinases from Bacillus megaterium (megaTYR) and Candidatus Nitrosopumilus koreensis (cnkTYR) as optimal candidates for recombinant expression. ${ }^{26,27}$ In particular, megaTYR was selected because several previous studies showed that the enzyme tolerated point mutations while retaining high activity to free tyrosine. ${ }^{17,27,28}$ The published crystal structures for megaTYR were beneficial for protein engineering, as they allowed rational design of point mutants and facilitated computational analysis of the protein (Figure 1a). ${ }^{27}$ In addition, cnkTYR was recently shown to have excellent monophenol monooxygenase activity and to tolerate low temperatures without significant loss in catalytic efficiency. ${ }^{19,26}$

In addition to the previously published work on protein $\mathrm{L},{ }^{22}$ the motivation for these explorations was the realization that abTYR was incapable of activating phenols attached to a single stranded DNA (ssDNA) substrate. In contrast, our first experiment with megaTYR showed significant levels of coupling between GFP and the phenol-DNA (Figure S1). This reaction occurs as two distinct steps: the initial activation of the phenol to the orthoquinone followed by addition of the nucleophile. These results suggested that some aspect of the DNA substrate was preventing activation by abTYR but was tolerated by megaTYR (Figure S1). We reasoned that this was likely the high degree of negative charge on the nucleotide substrate.

We next examined the substrate preference of the new tyrosinases, specifically with respect to their charge and steric tolerance. A peptide library with tyrosine residues at their C-termini was obtained, shown in Supplemental Table 1, which contained a variety of charged 
and neutral sequence elements. The peptides were coupled to Y200C GFP in 30 min reactions and analyzed via ESI-TOF MS to determine conversion to the modified peptide-protein conjugate. To ensure that peptide coupling was not biased by electrostatic interactions between GFP $(\mathrm{pI}=6.2)$ and the peptides, control reactions were run on a $p$-aminophenylalanine modified MS2 capsid, which has a pI of 8.0. These reactions reached similar levels of modification (Supplemental Figure S2). Comparing abTYR to the non-eukaryotic tyrosinases, it is readily apparent that abTYR is significantly more sensitive to negative charge (Figure 1D). In fact, abTYR shows no activity towards any peptide with 4 or more acidic residues adjacent to the terminal tyrosine. Also of note is the fact that megaTYR shows high activity towards all peptide substrates, with a drop in activity only in the case of the RRRRY peptide. These results supported the earlier challenge activating ssDNA substrates using abTYR, and suggest that megaTYR may serve as a highly permissive tyrosine activator. One additional observation of this study was that cnkTyr samples showed no discernable pattern of substrate specificity. 


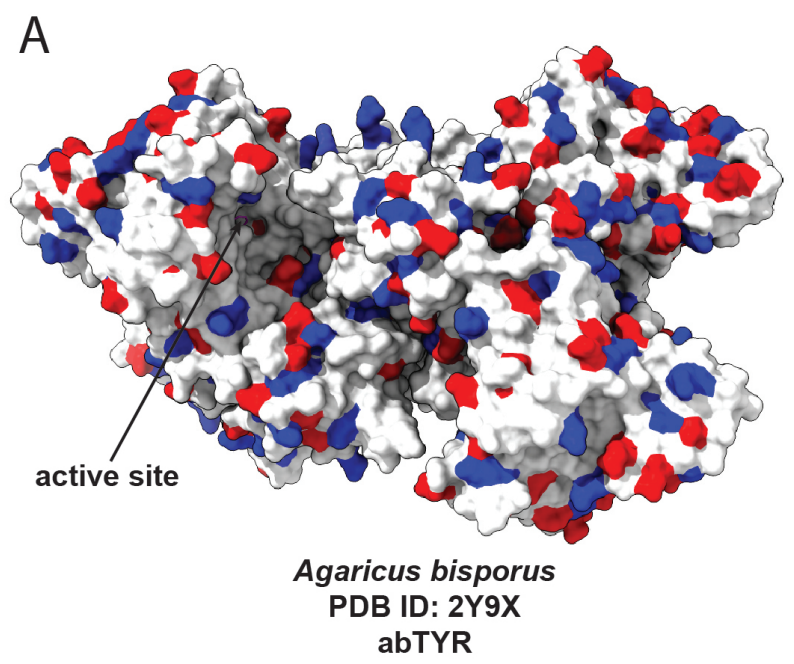

B

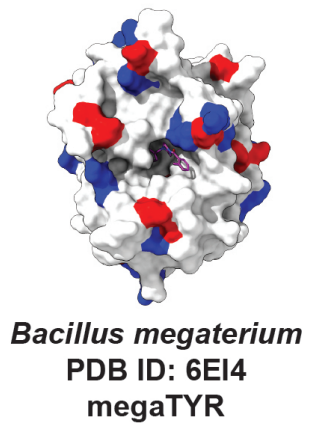

Peptide Screen

D

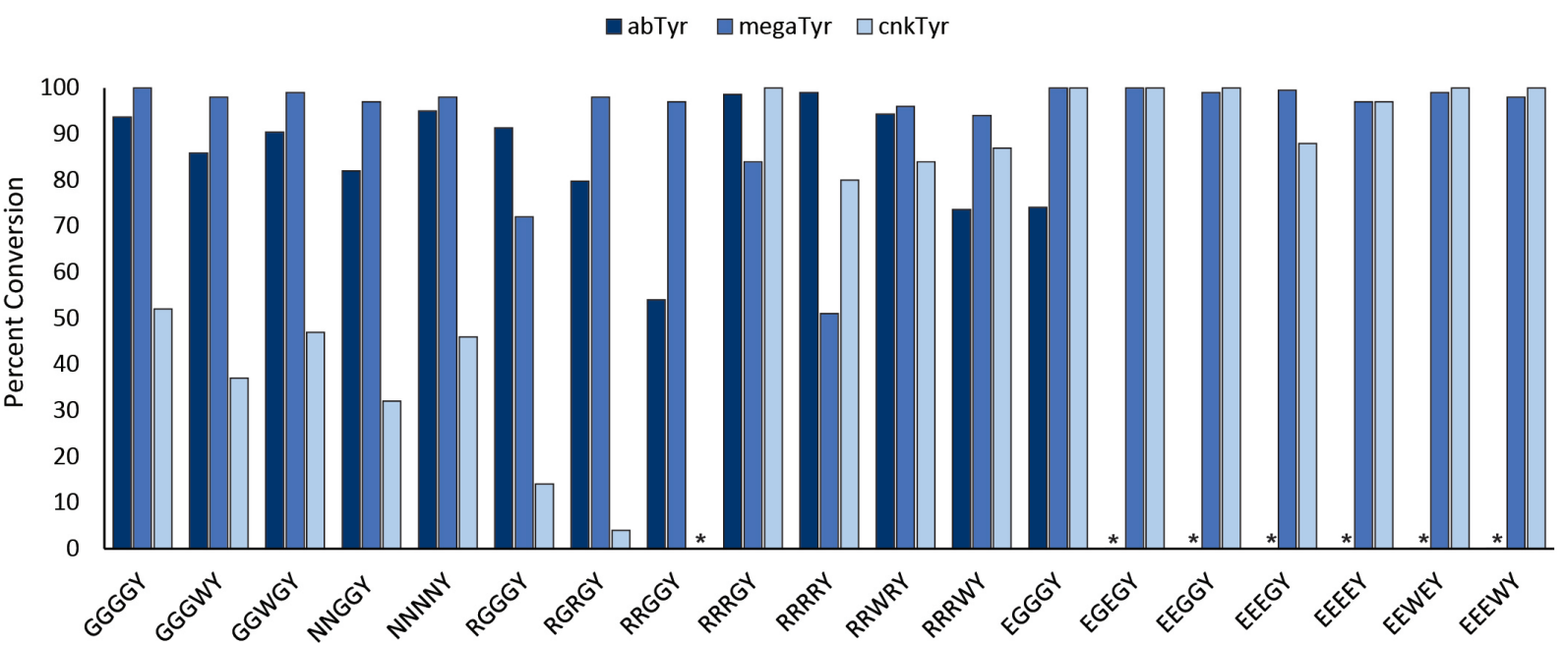

Figure 1: Structure and activity of tyrosinase enzymes from eukaryotic, procaryotic, and archaeal sources. A) Protein structure for abTYR from Agaricius bisporus with acidic residues in red and basic residues in blue. PDBID:2Y9X B) Protein structure for megaTYR from Bacillus megaterium with acidic residues in red and basic residues in blue. PDBID:6EI4 C) Protein structure for cnkTYR from Candidatus Nitrosopumilus koreensis with acidic residues in red and basic residues in blue. Structure was generated using the I-TASSER webserver. D) Peptide reaction screen showing percent conversion of Y200C sfGFP with the indicated peptide. All reactions carried out at $50 \mu \mathrm{M}$ Y200C sfGFP, $250 \mu \mathrm{M}$ peptide, and $12 \mathrm{U} / \mathrm{L}$ equivalent of either abTyr (dark blue), megaTYR (blue), or cnkTyr (light blue) in $50 \mathrm{mM} \mathrm{pH} 6.5$ phosphate buffer for $30 \mathrm{~min}$ before quench with $4 \mathrm{mM}$ tropolone and analysis via ESI-TOF-MS. Deconvoluted data were analyzed on www.chartograph.com with percent conversion calculated as percentage of peak area for the modified vs unmodified samples. Asterisks indicate where negligible amounts of protein modification were detected.

The structures of the three tyrosinases were compared to determine the origin of their 
selectivities, with cnkTyr represented by a homology model created using the I-TASSER server., ${ }^{25,26,29-32}$ abTYR is found as a hetero-tetramer and shows significant steric occlusion of the active sites (Figure 1A),${ }^{25}$ while megaTYR and cnkTYR are monomeric, and show a much more open active site. ${ }^{26,29}$ Due to their more predictable behaviours and established crystal structures, we focused our work on megaTYR and abTYR in subsequent experiments. However, further exploration or engineering of cnkTyr could yield a more specific phenol monooxygenase capable of acting with higher precision.

In the interest of improving megaTYR for even broader activity we performed an evolutionary conservation analysis of the megaTYR backbone in order to determine target positions for engineering. Using the ConSurf web server, the 100 closest non-redundant homologues of megaTYR were clustered and a multiple sequence alignment was prepared (Figure 2A). ${ }^{33-36}$ A normalized conservation score was calculated for each position using an empirical Bayesian methodology, which accounts for phylogenetic relationships between homologues in its construction of an evolutionary model. ${ }^{37}$ The evolutionary conservation was mapped onto the megaTYR structure and used to identify mutable anionic residues with low conservation scores (Figure 2B, Table S2). Position R209 was also chosen as a position of interest despite its mild conservation due to its established role in potentiating diphenolase activity, and its proximity to the active site (Figure 2C). ${ }^{27}$ We also chose to study R280 as a more distal mutable cationic residue with a low conservation score (Table S2). Previously studied mutants at positions V218 and F197 were not further investigated as their impact on megaTYR activity was not beneficial to our purpose of producing a more electrostatically targeted tyrosinase. ${ }^{17,28}$ 


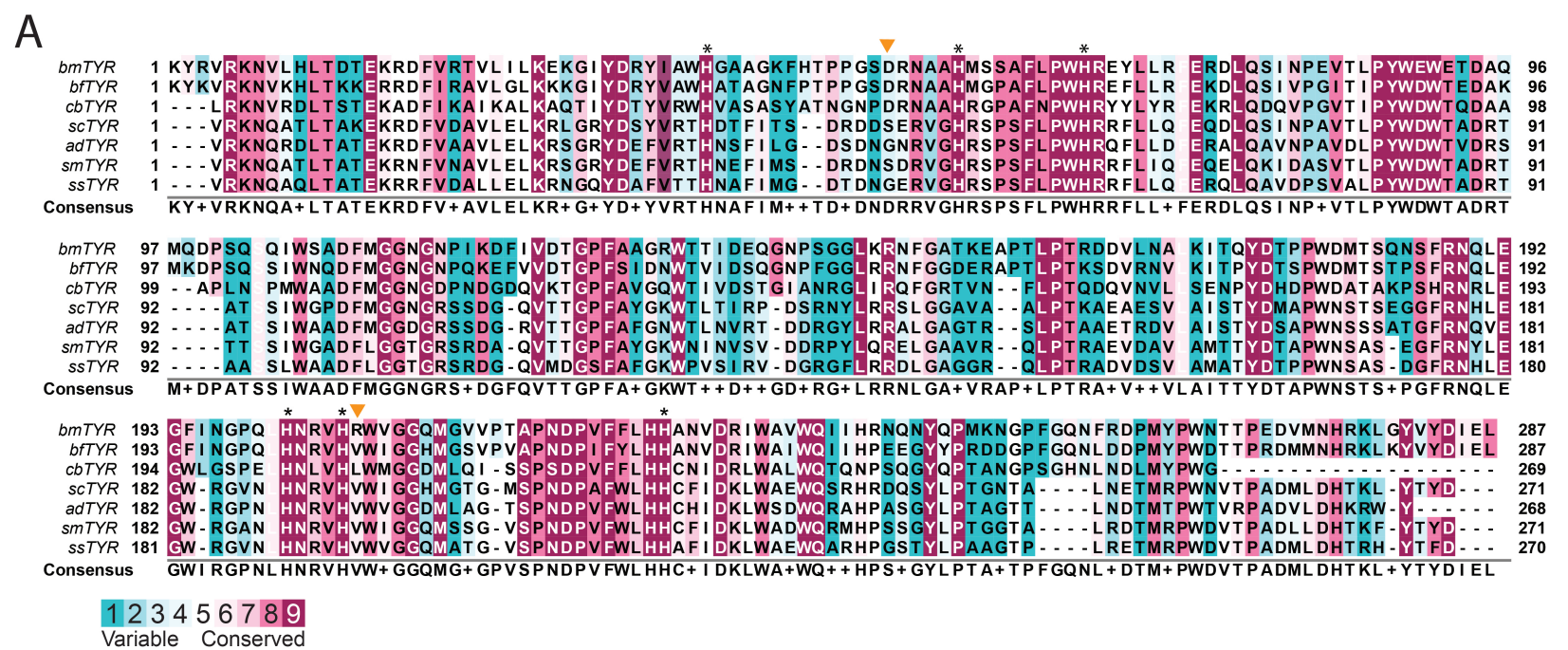

B
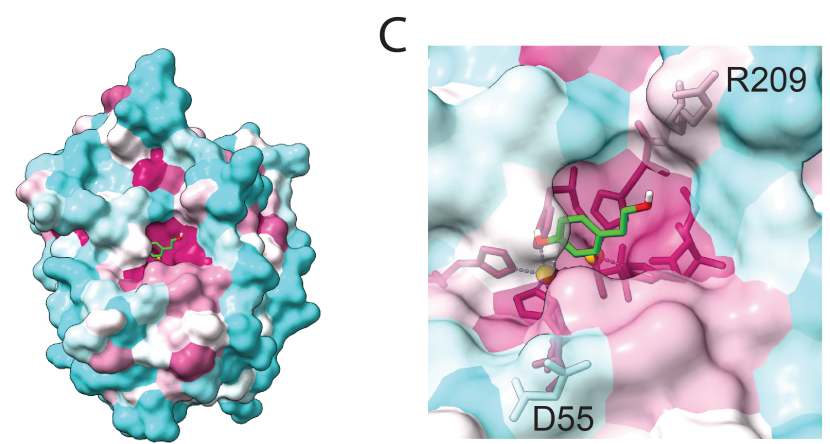

Figure 2: Evolutionary conservation of amino acids in megaTYR (bmTYR). A) Multiple sequence alignment of megaTYR backbone to its six nearest homologues. Residues are colored by conservation score calculated by using the evolutionary rate of 100 sequence homologues on the ConSurf web server. Highly conserved copper-binding residues are marked with an asterisk. Engineering sites are indicated with orange triangles. B) Conservation coloring mapped to the megaTYR structure. Bound substrate is colored in green. C) Active site of megaTYR with conservation coloring, copper ions shown in gold. Variable residues R209 and D55 surrounding the highly-conserved active site were selected as engineering targets to alter substrate scope.

The utility of modulating tyrosinase charge was explored in abTYR and megaTYR.

Mutants of megaTYR identified from literature and the conservation screen were modeled in Maestro using the charge mapping tool from the Epik and MacroModel modules to calculate the surface potential for each of the proteins compared to a point charge placed $14 \AA$ from the active site copper atoms (Figure 3A, Table S2). We reasoned that surface exposed polar and ionic residues proximal to the active site may be attractive targets, as they would have 
larger effects on active site potential than more distal residues, and modeled them in a similar manner (Table S3). We found that abTYR monomers had a net potential of $-4.4 \mathrm{~V}$ due to high numbers of acidic residues on their surfaces, corresponding to an isoelectric point (pI) of only 4.41. When the full active complex of abTYR is considered the net potential drops to $-15.7 \mathrm{~V} .{ }^{25}$ In contrast, megaTYR was shown to have a net potential of $+4.4 \mathrm{~V}$ and a pI of 8.66, correlating well with the observed charge preference. ${ }^{29}$

In accordance with our assumption that more proximal residues would have a larger impact on active site potential, we found that $\mathrm{R} 209 \mathrm{H}$ had a potential of $+3.0 \mathrm{~V}$, a significant reduction compared to the wild type, whereas $\mathrm{R} 280 \mathrm{H}$ has a much smaller impact on the electrostatics near the active site (Figure 3B, Table S2). Similarly, D55K had the largest impact on the active site potential among the $\mathrm{D} / \mathrm{E}$ to $\mathrm{K}$ mutants, corresponding to a potential of $+7.33 \mathrm{~V}$. Because of this, we also chose to model D55R to compare the effects of mutating anionic residues to lysine or arginine. While D55K had a potential of $+7.33 \mathrm{~V}$, D55R showed a slightly more positive net potential of $+7.5 \mathrm{~V}$, due to the higher pKa of arginine (Figure 3B, Table S2). 
A
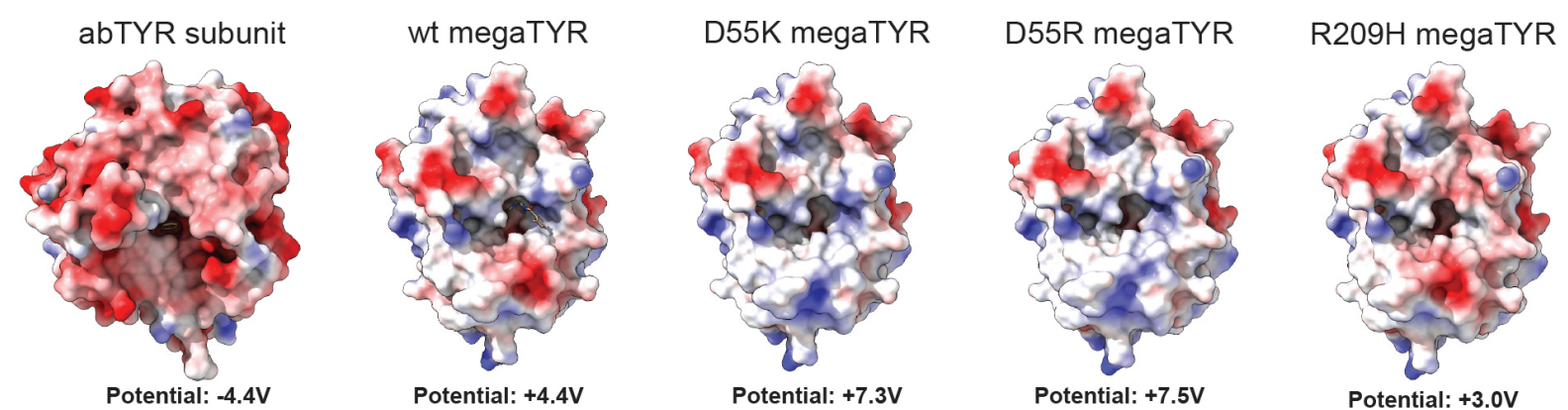

B

\begin{tabular}{c|c|c|c|c|c} 
Protein & Variant & $\begin{array}{c}\text { Isoelectronic } \\
\text { Point }(\mathbf{p l})\end{array}$ & $\begin{array}{c}\text { Net } \\
\text { Charge }\end{array}$ & $\begin{array}{c}\text { Solvated } \\
\text { Potential (V) }\end{array}$ & $\begin{array}{c}\Delta \text { Potential } \\
\text { (V) }\end{array}$ \\
\hline abTYR & Monomer & 4.41 & -13 & -4.4 & N/A \\
\hline abTYR & Complex & 4.41 & -76 & -15.7 & N/A \\
\hline megaTYR & Wild Type & 8.66 & +7 & +4.4 & N/A \\
\hline megaTYR & R209H & 8.02 & +6 & +3.0 & -1.4 \\
\hline megaTYR & D55K & 9.13 & +9 & +7.3 & +2.9 \\
\hline megaTYR & D55R & 9.15 & +9 & +7.5 & +3.1 \\
\hline megaTYR & E158K & 9.13 & +9 & +6.5 & +2.1 \\
\hline megaTYR & D183K & 9.13 & +9 & +6.5 & +2.1
\end{tabular}.

Figure 3: Calculations on tyrosinase mutants. A) Surface potential maps of abTYR and several megaTYR mutants with negative charge in red and positive charge in blue. B) Table showing results of charge potential calculations for the various tyrosinase mutants. For each tyrosinase a point charge was placed $14 \AA$ from the copper atoms within the active site and potential charge and $\mathrm{pI}$ were calculated using the Epik and Macromodel modules of Maestro developed by Schrödinger. $\Delta$ potential is calculated as the change in potential between the wild type and the listed mutant.

Based on data from the conservation screen and potential modelling we generated megaTYR with R209H, D55K, and D55R mutations. After initial screening at a tyrosinase concentration of $5 \mathrm{U} / \mathrm{L}$, it was observed that $\mathrm{R} 209 \mathrm{H}$ decreased the charge preference of megaTYR, while D55K and D55R were found to increase the preference for anionic substrates as shown by the higher level of modification with the EEEEY peptide (Figure 4B, structures with residues highlighted in Figure 4A). To assess the degree of substrate preference we ran competition assays containing the EEEEY and RRRRY peptides in equal concentrations. In these assays abTYR only showed activity towards RRRRY, while R209H 
showed equal preference for the two (Figure 4C). Interestingly, wild type megaTYR showed a 90\% preference for EEEEY, while the D55K mutant showed a 95\% preference and D55R a surprising $>99 \%$ preference for the anionic peptide (Figure 3C). As D55K experienced expression challenges, and was not capable of complete substrate differentiation, we chose to focus on D55R as the higher performing mutant.

We then performed a full substrate screen on each megaTYR variant (wild type, R209H, and D55R) at the same concentration as the initial substrate screen (12 U/L) and found that these mutations only had a significant effect on the enzymatic activity towards highly charged peptide substrates. Interestingly, D55R megaTYR exhibited low conversion for the RRRRY peptide, but retained high levels of activity towards the less highly charged cationic peptides (Figure 4D). Generating sequence orthogonal tyrosinases could enable the facile creation of complex multi-domain proteins by coupling anionic and cationic tagged subunits sequentially. This could be done in a manner similar to peptide synthesis but using entire proteins as building blocks. The controlled production of multi-protein polymers could be an enabling technology for protein based materials, biomedical technologies, and enzyme engineering. 


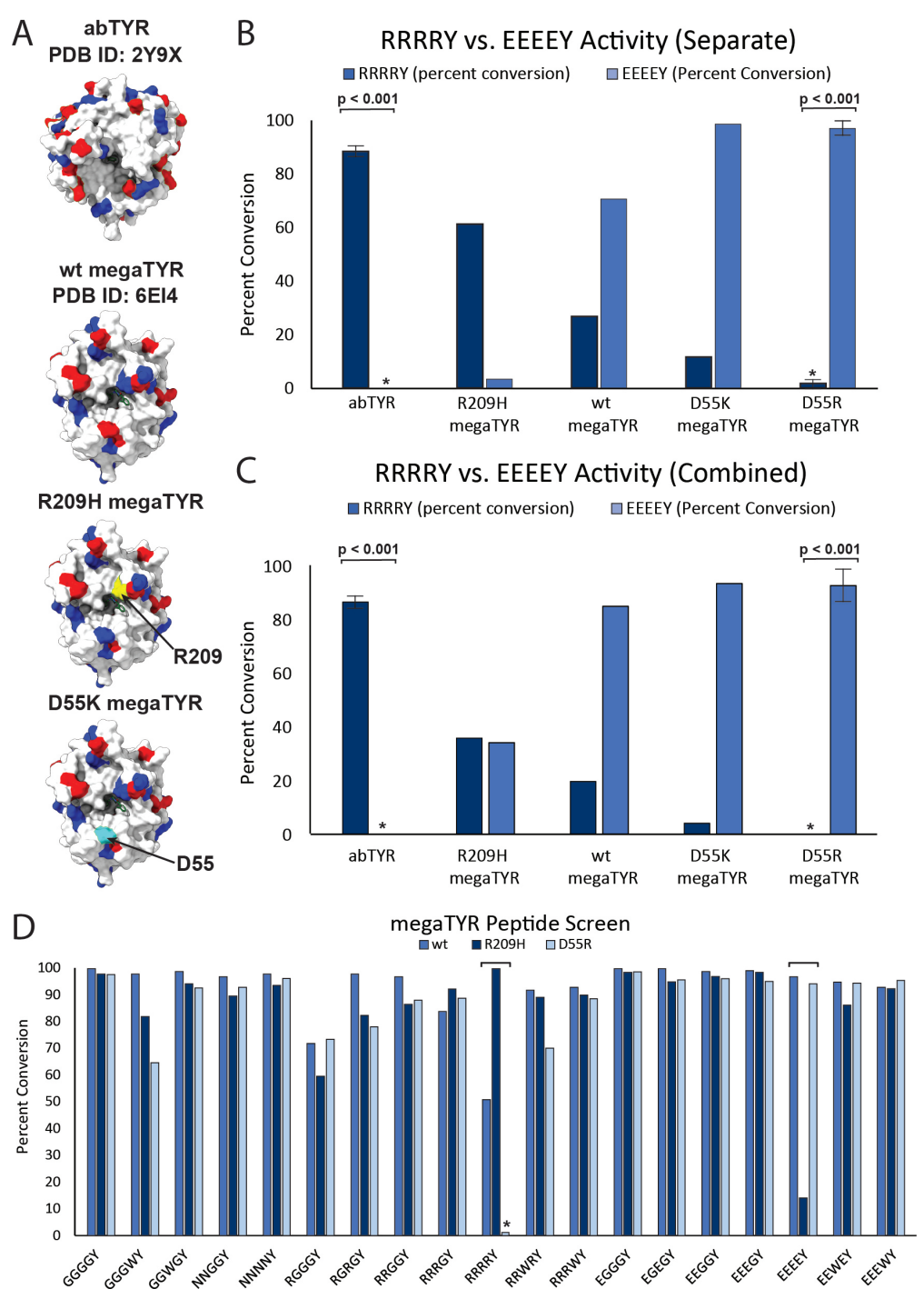

Figure 4: Point mutants of megaTYR and their impact on substrate preference. A) Structural comparison of abTYR vs megaTYR with locations of point mutations highlighted. R209 is shown in yellow, D55 in blue. Structures show acidic (Asp and Glu) residues in red and basic ( Lys and Arg) residues in blue. B) Comparison of reactivity of abTYR vs single mutants of megaTYR on peptides EEEEY and RRRRY. Reactions were run for 30 min at RT in $50 \mathrm{mM} \mathrm{pH} 6.5$ phosphate buffer, $5 \mathrm{U} / \mathrm{L}$ tyrosinase, $50 \mu \mathrm{M}$ Y200C sfGFP and $250 \mu \mathrm{M}$ peptide. Reactions were quenched with $4 \mathrm{mM}$ tropolone. C) Competition reactions between RRRRY and EEEEY peptides to assess substrate preference of tyrosinase mutants. Reactions were run for $30 \mathrm{~min}$ at RT in $50 \mathrm{mM} \mathrm{pH} 6.5$ phosphate buffer, $5 \mathrm{U} / \mathrm{L}$ tyrosinase, $50 \mu \mathrm{M}$ Y200C sfGFP and $250 \mu \mathrm{M}$ of each peptide. Reactions were quenched with $4 \mathrm{mM}$ tropolone. D) Peptide reaction screen showing percent conversion of Y200C sfGFP with the indicated peptide. All reactions were run at $50 \mu \mathrm{M}$ Y200C sfGFP, $250 \mu \mathrm{M}$ peptide, and $12 \mathrm{U} / \mathrm{L}$ equivalent of either wt megaTYR (blue), R209H megaTYR (dark blue), or D55R megaTYR (light blue) in $50 \mathrm{mM} \mathrm{pH} 6.5$ phosphate buffer for 30 min before quenching with $4 \mathrm{mM}$ tropolone and analysis via ESI-TOF-MS. Deconvoluted data were analyzed on www.chartograph.com with percent conversions calculated as percentage of peak area percentages for the modified vs unmodified species. 
Although the megaTYR mutants to date were not fully prevented from acting on cationic substrates, the range in selectivity between abTYR and D55R megaTYR proved a tantalizing target. To test this, the cysteine-containing Y200C sfGFP was modified with EEEEY and RRRRY C-terminal tags, which should be unreactive with abTYR, and D55R megaTYR, respectively (Figure S3, S4). After purification, the Y200C sfGFP-EEEEY (GFP-E4Y) was exposed to abTYR for $30 \mathrm{~min}$ in a variety of conditions. Notably, the mushroom tyrosinase was able to append GGGGY and RRRRY peptides to the GFP-E4Y without oxidizing the EEEEY tag. In addition, exposing the GFP-E4Y to abTYR resulted in no discernable oxidation by ESI-MS. This aligns with our previous peptide screens, and suggests that the EEEEY tag is not succeptible to abTYR activation (Figure S3). Similarly, Y200C sfGFPRRRRY (GFP-R4Y) was exposed to D55R megaTYR under similar conditions, with the EEEEY peptide used in place of the RRRRY peptide. Similarly to abTYR, D55R megaTYR was able to selectively oxidize the added peptides without modifying the tyrosine tag on the GFP-R4Y. Reaction selectivity was further confirmed when exposure of GFP-R4Y to D55R megaTYR alone did not result in any oxidation (Figure S4). Together these data suggest that abTYR and D55R megaTYR can be used for CDSAT on proteins and peptides.

To further validate reaction orthogonality we next exposed the GFP-E4Y to a phenolbiotin in the presence of abTYR and showed selective oxidation of the small molecule to afford the GFP-E4Y-biotin conjugate (Figure 5E). In parallel, we modified GFP-E4Y with a biotin-maleimide as a positive control (Figure 5D). After purification using a $10 \mathrm{kDa}$ MWCO spin concentrator, both the maleimide and phenol GFP-E4Y-biotin were combined with Y200C sfGFP and 12 U/L D55R megaTYR for $30 \mathrm{~min}$ and analyzed via ESI-TOFMS. We observed over $70 \%$ conversion to the trimer composed of two GFP proteins and a biotin molecule, making this one of the first techniques capable of creating 3-component fusions without the need for solid support tethering or removable protective groups (Figure 5F-G). In addition, some higher order modifications appeared, arising from residual disulfide formation between unreacted thiols in the first step. 


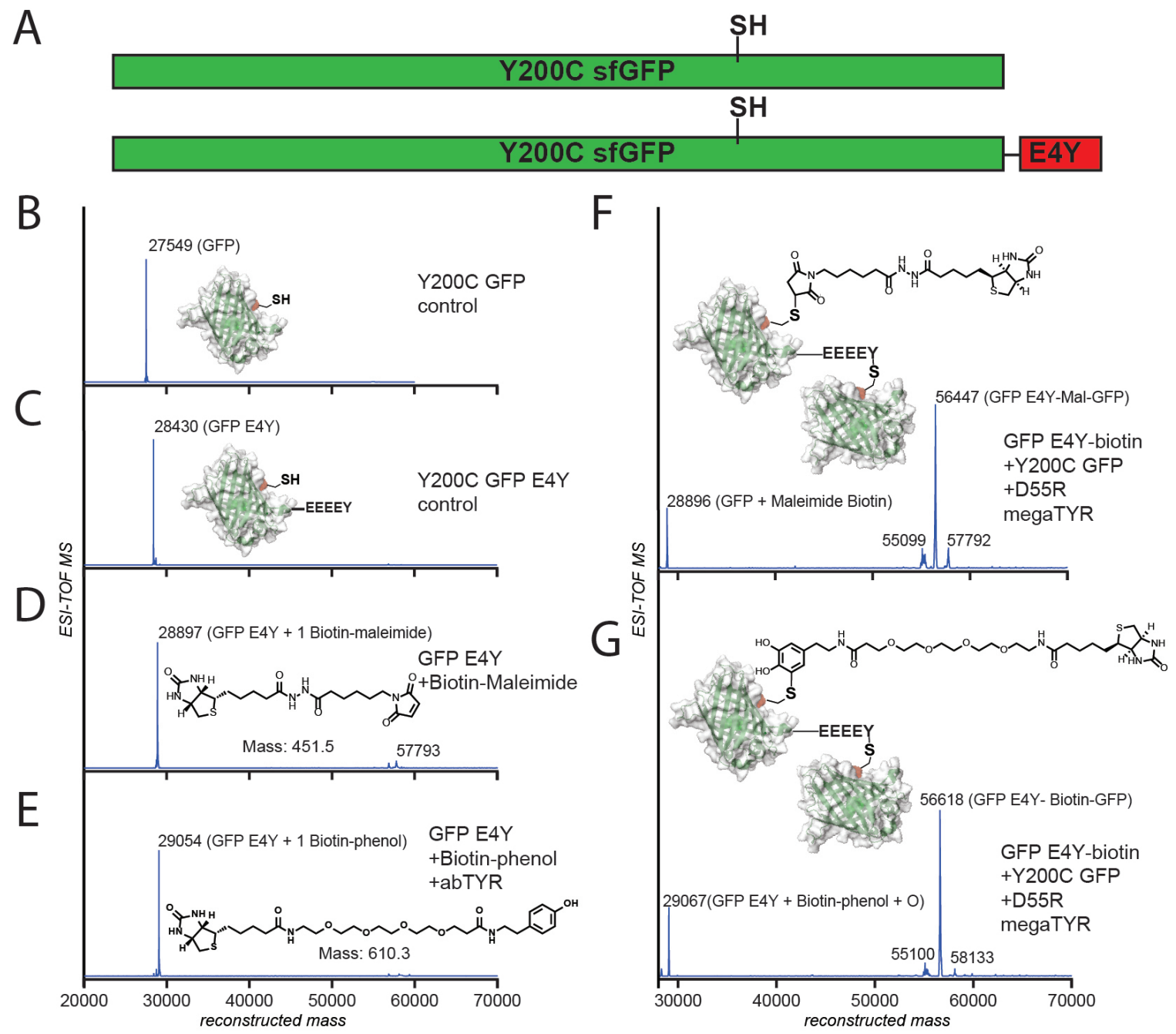

Figure 5: Coupling of two proteins to a small molecule. A) Scheme depicting the construction of a cysteine GFP (Y200C GFP), as well as a negative tyrosine tagged cysteine GFP (GFP E4Y). B,C) ESI-MS data for unmodified Y200C GFP and GFP E4Y respectively. D) ESIMS of GFP E4Y modified with biotin maleimide. Biotin-maleimide coupled to GFP E4Y by combining $50 \mu \mathrm{M}$ GFP E4Y with $500 \mu \mathrm{M}$ biotin-maleimide at pH 7.5 for $2 \mathrm{~h}$. E) GFP E4Y was coupled to biotin-phenol by combining $50 \mu \mathrm{M}$ GFP E4Y with $200 \mu \mathrm{M}$ biotin-phenol with $12 \mathrm{U} / \mathrm{L}$ abTYR in $50 \mathrm{mM}$ phosphate $\mathrm{pH} 6.5$ for $30 \mathrm{~min}$ at RT. Product mass expected = 29,054 Da. F-G) Reaction of $10 \mu \mathrm{M}$ GFP-E4Y-biotin with $50 \mu \mathrm{M}$ Y200C GFP with $12 \mathrm{U} / \mathrm{L}$ megaTYR for $30 \mathrm{~min}$ at RT. Expected mass for GFP+GFP+ maleimide biotin = 56,446 Da and for GFP+GFP phenol = 56,618 Da.

To evaluate the potential of an iterative tyrosinase sequence for the creation of protein trimers, GFP-E4Y was combined with a MYGGS-tagged nano-luciferase and $12 \mathrm{U} / \mathrm{L}$ abTYR to activate the neutral luciferase tag selectively (Figure 6A-C). Clean conversion to the GFP-E4Y-nano-luciferase dimer was observed, with no excess oxidation. To remove any 
unreacted starting material, the solution was purified using a $50 \mathrm{kDa}$ MWCO spin concentrator (Figure 6C). As a third component, the thiol-containing S152C-mCherry was added to the dimer solution with $12 \mathrm{U} / \mathrm{L}$ D55R megaTYR to activate the EEEEY tag on the GFP. This strategy led to smooth conversion to the mCherry-GFP-luciferase trimer (Figure 6D). We saw $100 \%$ conversion from the dimer to the final product, indicating that megaTYR is capable of catalyzing tyrosinase oxidation on anionic tags even in the presence of multiprotein complexes. The tri-functional nature of the construct identity was further validated by luminescence and fluorescence measurements. Upon introducing the nanoLuc substrate, FRET was observed between the luciferase, GFP, and mCherry subunits. In addition, direct excitation of the GFP fluorophore led to emission from the mCherry segment via energy transfer (Figure S5). This new capability to oxidize tyrosine residues in different charge contexts iteratively highlights the potential of this system to generate complex protein products for future applications. 
A
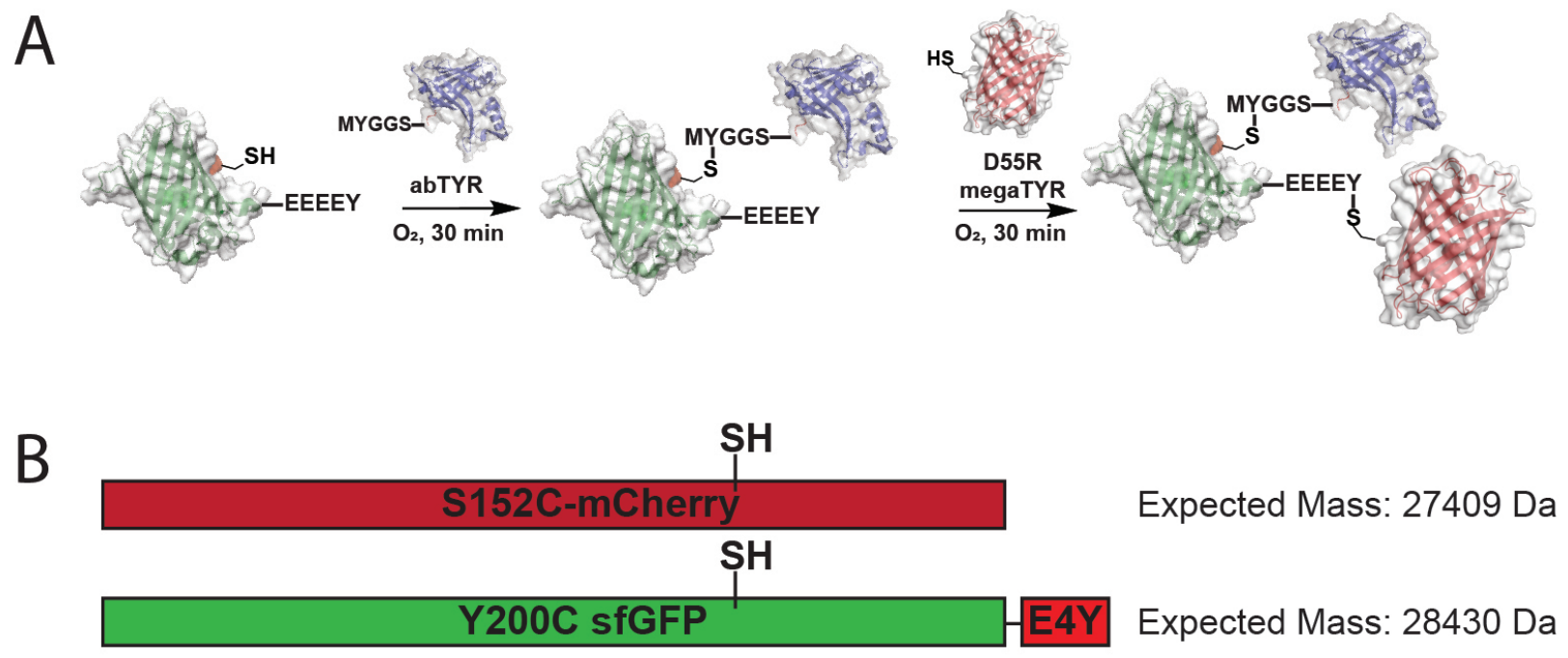

MYGGS Nano Luciferase Expected Mass: 20282 Da
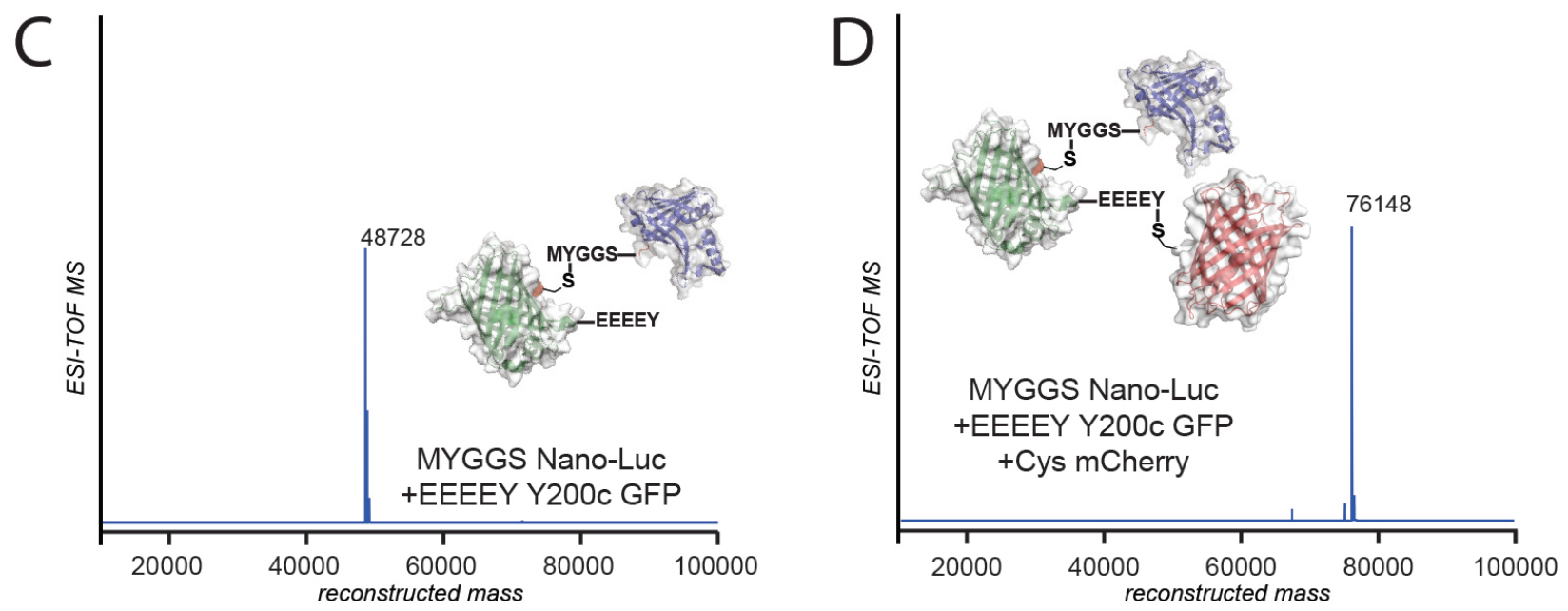

Figure 6: Use of tyrosinase charge selectivity for the synthesis of ternary protein complexes. A) Reaction scheme showing the use of sequential reactions with abTYR and megaTYR to couple 3 proteins together. B) Protein sequence maps for S152C mCherry (mCherry), Y200C GFP with EEEEY tag (GFP E4Y), and a MYGGS tagged nano Luciferase (nanoLuc). C) Reaction of $50 \mu \mathrm{M}$ GFP-E4Y with $100 \mu \mathrm{M}$ nanoLuc and $12 \mathrm{U} / \mathrm{L}$ abTYR for $30 \mathrm{~min}$. GFP + nanoLuc structure shown above chart. Expected mass $=48,728$ D) GFP E4Y-nanoLuc (10 $\mu \mathrm{M})$ purified by spin down using a $50 \mathrm{kDa}$ MWCO spin concentrator combined with $100 \mu \mathrm{M}$ Y200C GFP and $12 \mathrm{U} / \mathrm{L}$ megaTYR for 30 min at RT converted E4Y GFP-nanoLuc to the mCherry-GFP-nanoLuc trimer after purification using $50 \mathrm{kDa}$ MWCO spin filter. Trimer structure shown above spectrum. Expected mass $=76,153$ Da. 


\section{Conclusion}

Here we show that recombinantly expressed tyrosinases are successful activators of terminal tyrosine residues on a variety of protein and peptide substrates. The results from the megaTYR mutant screen show that bacterially derived tyrosinases possess sufficient selectivity to mediate protein-protein coupling reactions through tyrosine-cysteine bond formation, and can be engineered to alter their substrate preferences. The success at modulating the charge preference of this enzyme indicates that it is tolerant toward mutation and can be engineered to achieve orthogonal reactivity preferences to those of abTYR. The result of these efforts is the ability to sequentially activate tyrosine residues based on their charge context, or CDSAT. The protein trimers created using CDSAT show that minimal engineering is required to produce a system capable of creating higher-order protein constructs. Such multivalent conjugates have tremendous potential for materials, therapeutic, and diagnostic applications. 


\section{Acknowledgement}

The authors thank the Zhang lab for making available the I-TASSER server:

https://zhanglab.ccmb.med.umich.edu/I-TASSER/. The authors also thank Dr. Kathy Durkin and Dr. Dave Small and the MGCF Facility for providing computational resources for the electrostatics calculations. Computational work was supported by NIH Grant: S10OD023532. This work was supported by NIH Grant: R01 GM138693.

\section{Supporting Information Available}

Unless otherwise noted, all chemicals were obtained from commercial sources and used without further purification. Water $\left(\mathrm{ddH}_{2} \mathrm{O}\right)$ used in biological procedures or as a reaction solvent was de-ionized using a NANOpure purification system (Barnstead, USA). Peptides were purchased from GenScript (Piscataway, NJ). All oligonucleotides were purchased from Integrated DNA Technologies (Coralville, IA). Terrific broth used in protein expression was purchased from Mediatech Inc. (Maryland, VA). Spin concentrators were obtained from EMD Millipore (Millipore, Billerica, MA).

\section{Instruments and Characterization}

Mass Spectrometry. Time of flight electrospray ionization mass spectrometry (TOF-ESIMS) of proteins was performed using an Agilent 1260 series liquid chromatography (LC) system with an Agilent 6530C Q-TOF LC-MS system (Santa Clara, CA). For mobile phases, the system utilized Milli-Q $\mathrm{H}_{2} \mathrm{O}$ with $0.1 \%$ (v/v) formic acid (solvent A) and HPLC grade ACN with $0.1 \%(\mathrm{v} / \mathrm{v})$ formic acid (solvent B). Before submission to analysis, each sample was desalted and passed through a $0.22 \mu$ m cellulose acetate centrifugal filter. Samples of 2 $-10 \mu \mathrm{L}$ were injected, corresponding to 0.2 to $1.0 \mu \mathrm{g}$ of protein. The sample was separated on a Proswift RP-4H (monolithic phenyl, $1.0 \mathrm{~mm} \times 50 \mathrm{~mm}$, Dionex) analytical column with a flow rate of $0.30 \mathrm{~mL} / \mathrm{min}$ and a gradient of $5-100 \%$ solvent $\mathrm{B}$ in solvent A over 8 min. Agilent Mass Hunter Workstation software (Qualitative Analysis Version B.10.0, Build 
10.0, Agilent Technologies Inc.(C) 2020) was used to extract total ion chromatograms from raw data and the Maximum Entropy deconvolution algorithm was used to reconstruct the original analyte masses. CSV files of spectra were plotted using the open source Chartograph software (www.chartograph.com). Integration of an unmodified protein sample served as an internal standard for determining conversion.

\section{Size Exclusion HPLC:}

HPLC purification of Encapsulated proteins was performed on an Agilent 1100 Series HPLC Systems (Agilent Technologies, USA) outfitted with an Agilent 1200 series automatic fraction collector. Sample analysis for all HPLC experiments was achieved with an inline diode array detector (DAD) and in-line fluorescence detector (FLD). HPLC of capsids and proteins was accomplished using a BioSep-SEC s4000 column 300 x 7.8 mm column (Phenomenex, Torrance, CA). The samples were eluted in isocratic flow of $10 \mathrm{mM}$ or $100 \mathrm{mM}$ $\mathrm{pH} 6.8$ phosphate buffer at $1 \mathrm{~mL} / \mathrm{min}$.

\section{UV-Vis Spectroscopic Measurements:}

UV-Vis spectroscopic measurements were conducted on a Thermo Scientific nanoDrop 1000 scan benchtop spectrophotometer (Thermo Scientific, Wilmington, DE). Spectra were collected in Proteins and Labels mode from 200-800nm, while direct protein concentrations were calculated using Protein A280.

\section{Gel Analyses:}

For protein analysis, sodium dodecyl sulfate-polyacrylamide gel electrophoresis (SDSPAGE) was performed in a NuPAGE apparatus (Life Technologies, Hercules, CA), using a $4-12 \%$ precast linear gradient polyacrylamide gel (Bio-Rad, Hercules, CA). All protein electrophoresis samples were heated for $10 \mathrm{~min}$ at $75{ }^{\circ} \mathrm{C}$ in the presence of 1,4-dithiothreitol (DTT) to ensure reduction of disulfide bonds. Gels were run for 30 min at $200 \mathrm{~V}$ to separate the bands. Commercially available markers (Bio-Rad) were applied to at least one lane of each gel for assignment of apparent molecular masses. Visualization of protein bands was accomplished by staining with Coomassie Brilliant Blue R-250 (Bio-Rad). Gels were 
visualized on Gel-Doc EZ Imager (Bio-Rad).

For PCR reactions products were run on a $2 \%$ agarose gel in TEA buffer with 1:10000 SyberSafe DNA gel stain (ThermoFisher Scientific, Wilmington, DE). PCR samples were incubated for 5 min with 6x Orange loading buffer (Orang Loading Dye, Thermo Scientific, Waltham, MA) before application to the gel. Gels were run for $45 \mathrm{~min}$ at $120 \mathrm{~V}$ to separate bands. Commercially available markers (1kb DNA Ladder, New England BioLabs, Ipswich, MA) were applied to at least one lane of each gel for assignment of apparent mass. Visualization of DNA bands was accomplished using a Gel-Doc EZ Imager (Bio-Rad).

\section{Fluorimeter Measurements:}

Fluorimeter measurements were conducted on a Fluoromax-4 Spectrofluorometer (HORIBA Scientific). Proteins were placed in a cuvette with $1 \mathrm{~mL}$ of $50 \mathrm{mM} \mathrm{pH} 6.5$ phosphate with constant stirring using magnetic stir bar. Final protein concentration for all experiments was $250 \mathrm{nM}$ which was obtained by diluting $5 \mu \mathrm{L}$ of $50 \mu \mathrm{M}$ stock in $995 \mu \mathrm{L} 50 \mathrm{mM} \mathrm{pH} 6.5$ phosphate. For nanoLuciferase assay, $5 \mu \mathrm{L}$ of NanoLuc Substrate (Promega) was diluted in $95 \mu \mathrm{L}$ of NanoLuc Buffer (Promega), then added in $5 \mu \mathrm{L}$ aliquots to the preparred sample already inserted into the Fluorimeter. Measurements were taken after addition as quickly as possible measuring from $400 \mathrm{~nm}$ to $700 \mathrm{~nm}$ at $5 \mathrm{~nm}$ increments. For direct fluorescence measurements readings were taken by exciting at $485 \mathrm{~nm}$ with a $5 \mathrm{~nm}$ window and monitoring emission from 510-700 nm for GFP. For mCherry detection readings were taken by exciting at $585 \mathrm{~nm}$ with a $5 \mathrm{~nm}$ window and monitoring emission from $610-700 \mathrm{~nm}$.

\section{Protein Expression and Purification:}

\section{Expression and purification of prokaryotic tyrosinases:}

A $10 \mathrm{~mL}$ overnight culture of BL21 (DE3) Codon Plus RIL E. coli in Terrific Broth (TB) medium with $50 \mu \mathrm{g} / \mathrm{mL}$ kanamycin was inoculated into a $2.8 \mathrm{~L}$ trident Erlenmeyer flask with $1 \mathrm{~L}$ of sterile TB with kanamycin. The culture was incubated at $37^{\circ} \mathrm{C}, 220 \mathrm{rpm}$ and cell density was monitored until the O.D. at $600 \mathrm{~nm}$ was between 0.4 and 0.6 . The cells were then induced by adding IPTG to a final concentration of $0.4 \mathrm{mM}$ and subsequently 
incubated for another $12 \mathrm{~h}$ at $37{ }^{\circ} \mathrm{C}$. The cells were then pelleted and stored at $-80{ }^{\circ} \mathrm{C}$.

The cell pellet was thawed on ice in lysis buffer $(500 \mathrm{mM} \mathrm{NaCl}, 20 \mathrm{mM}$ imidazole, $20 \mathrm{mM}$ Tris-HCl pH 7.5) and PMSF (0.1 mM), and cells were lysed by sonication for $10 \mathrm{~min}(2 \mathrm{~s}$ on, 4 s off, $60 \%$ amplitude, with a Fisher Scientific Sonic Dismembrator). The cellular debris was removed with centrifugation $\left(17,000 \mathrm{~g}, 15 \mathrm{~min}, 4^{\circ} \mathrm{C}\right)$, and the supernatant was applied to a Ni-NTA gel spin column (ThermoFisher HisPur). The column was washed 3 times with $6 \mathrm{~mL}$ of lysis buffer (lysis buffer without PMSF), and fractions were collected. The protein was then eluted using four $6 \mathrm{~mL}$ portions of elution buffer $(500 \mathrm{mM} \mathrm{NaCl}, 500 \mathrm{mM}$ imidazole, $20 \mathrm{mM}$ Tris- $\mathrm{HCl}, 0.02 \mathrm{mM} \mathrm{CuSO}_{4}, \mathrm{pH}$ 7.5) for a total of $24 \mathrm{~mL}$. All fractions were analyzed using SDS-PAGE, and the tyrosinase-containing fractions were collected. The buffer was exchanged for protein storage buffer (PBS with $15 \%$ glycerol and $0.02 \mathrm{mM} \mathrm{CuSO}_{4}$ ) using a spin concentrator (10 KDa MWCO, $15 \mathrm{~mL}$, Amicon Ultra) and then concentrated to 150 $\mu \mathrm{M}$. The tyrosinase solutions were stored at $-80{ }^{\circ} \mathrm{C}$.

Expression and purification of Y200C-sfGFP variants:

After sequence verification, a $10 \mathrm{~mL}$ overnight culture of BL21 (DE3) Codon Plus RIL E. coli in TB medium with $50 \mu \mathrm{g} / \mathrm{mL}$ kanamycin was inoculated into a $2.8 \mathrm{~L}$ trident Erlenmeyer flask with $1 \mathrm{~L}$ of sterile Terrific Broth (TB) medium and kanamycin. The cultures were grown at $37^{\circ} \mathrm{C}$ with $220 \mathrm{rpm}$ shaking until O.D. at $600 \mathrm{~nm}$ reached $0.6-0.8$. To induce expression, IPTG was added from a 1.0 M stock to a final concentration of $1.0 \mathrm{mM}$. The cultures were incubated at $37{ }^{\circ} \mathrm{C}$ for $12-16 \mathrm{~h}$. Cells were then incubated for another $12-16 \mathrm{~h}$ at $37{ }^{\circ} \mathrm{C}$ and pelleted. After freezing at $-80{ }^{\circ} \mathrm{C}$, cell pellets were resuspended in $15 \mathrm{~mL}$ of an equilibration buffer $(20 \mathrm{mM}$ sodium phosphate, $2 \mathrm{M} \mathrm{NaCl}, 20 \mathrm{mM}$ imidazole at $\mathrm{pH}=7.4)$ and then lysed via sonication for $30 \mathrm{~min}$ at $60 \%$ amplitude. Cell lysate was spun down at 14,000 rpm for 30 min, then the supernatant decanted before loading on to a HisTrap FF Crude column. After binding, the bound protein was washed with 4 portions of two resin bed volumes of wash buffer $(20 \mathrm{mM}$ sodium phosphate, $300 \mathrm{mM} \mathrm{NaCl}, 25 \mathrm{mM}$ imidazole at $\mathrm{pH}=7.4)$ and subsequently eluted with four resin bed volumes of elution buffer (20 mM sodium phosphate, 
$300 \mathrm{mM} \mathrm{NaCl}, 250 \mathrm{mM}$ imidazole at $\mathrm{pH}=7.4$ ). The purified sfGFP variant was then spun concentrated into $50 \mathrm{mM}$ phosphate buffer at $\mathrm{pH} 7.2$ using 10k MWCO filters. Purified sfGFP samples were flash frozen and stored at $-20{ }^{\circ} \mathrm{C}$ until use. Purified protein was spin concentrated into $20 \mathrm{mM}$ phosphate buffer at pH 7.0 using 10k MWCO spin filters prior to reaction.

Expression and purification of paF MS2:

Glycerol stocks of E. coli containing plasmids for the T19paF mutant of MS2 were generously provided by Ioana Aanei. The T19paF MS2 expression was carried out in minimal media following the published protocol. ${ }^{38-40}$ The pellets were thawed and re-suspended in $20 \mathrm{ml}$ of $20 \mathrm{mM}$ taurine buffer (pH 9) containing $6.5 \mathrm{mM} \mathrm{DTT}, 6 \mathrm{mM} \mathrm{MgCl}_{2}$, and $10 \mu \mathrm{g} / \mathrm{ml}$ each of DNase and RNase. Following sonication for $10 \mathrm{~min}$, the cells were spun down for 45 min at 11,000 rpm. Next, the supernatant was applied to a DEAE-Sephadex column (GE Healthcare, Little Chalfont, United Kingdom). In 20 mM pH 9 taurine buffer, MS2 eluted first from the DEAE column and was collected and precipitated using an equal volume of saturated aqueous ammonium sulfate. The protein pellets were re-suspended in $10 \mathrm{mM}$ pH 7.2 phosphate buffer and applied to a Sephacryl S1000 column (GE Healthcare). The fractions containing MS2 were then collected and concentrated using Amicon Ultra $100 \mathrm{kDa}$ MWCO centrifugal concentrators (Millipore). A yield of $3 \mathrm{mg} / \mathrm{L}$ culture was obtained for T19paF MS2 following two rounds of purification.

MS2 paF sequence:

$\mathrm{T}$ in red represents the $\mathrm{T} 19 \mathrm{paF}$ mutation site:

\section{ASNFTQFVLV DNGGTGDVTV APSNFANGVA EWISSNSRSQ AYKVTCSVRQ SSAQNRKYTI}

61 KVEVPKVATQ TVGGVELPVA AWRSYLNMEL TIPIFATNSD CELIVKAMQG LLKDGNPIPS

\section{AIAANSGIY}

Expression of nano luciferase (nanoLuc):

The gene encoding nanoLuc was cloned from plasmids provided by Promega (pNL1.1) 
using primers that encoded the specified N- or C-terminal modifications as well as a golden gate cloning site. The modified product was then transferred into a modified pet28b cloning vector (pECH081) and transformed into Rosetta DE3 pLysS E. coli. Overnight cultures were grown at $37{ }^{\circ} \mathrm{C}$ in $\mathrm{LB}$ with $50 \mathrm{mM}$ kanamycin, then transferred into $1 \mathrm{~L}$ TB media with 50 mM kanamycin. Once cultures reached an OD600 of 0.6 protein production was induced by addition of $100 \mathrm{mg} / \mathrm{mL}$ IPTG and left shaking overnight at $37^{\circ} \mathrm{C}$. After $16 \mathrm{~h}$ of incubation, the cultures were centrifuged at $7000 \mathrm{x} \mathrm{g}$, and the pellets collected were then re-suspended in $50 \mathrm{mM}$ phosphate, $200 \mathrm{mM} \mathrm{NaCl}, 20 \mathrm{mM}$ imidazole, pH 7 buffer. Samples were lysed by sonication, then centrifuged at $17000 \mathrm{x}$ g. The supernatant was collected and run through a HiTrap NiNTA column from GE in a miniAkta, and eluted with a $50 \mathrm{mM}$ phosphate, 200 $\mathrm{mM} \mathrm{NaCl}, 250 \mathrm{mM}$ imidazole buffer at $\mathrm{pH}$ 7. Purified nanoLuc samples were flash frozen and stored at $-20{ }^{\circ} \mathrm{C}$ until use. Purified protein was spin concentrated into $20 \mathrm{mM}$ phosphate buffer at pH 7 using 10k MWCO spin filters prior to reaction.

\section{Protein Sequences and DNA Manipulation:}

Protein gene blocks were ordered from Integrated DNA Technologies, codon-optimized for E. coli expression. Bsa1 cut sites were present at either end of the gene sequence for cloning into the pET28b golden gate entry. ${ }^{41}$ This vector enabled green / white screening for colonies successfully transformed with plasmids bearing the inserted gene and provided resistance to kanamycin. PCR primers used to make megaTYR and sf-GFP variants are listed in Supporting Table 2.

Mutagenisis was performed using a combination of Gibson Assembly and Golden Gate based approaches. In the Gibson Assembly based approach, two sets of primers were used to create two linear half plasmids bearing the $\mathrm{R} 209 \mathrm{H}$ mutation, which were then recyclized using a standard Gibson Assembly protocol. In the Golden Gate approach, two primers were used to create a D55K and D55R linearized plasmids flanked by BsaI cutsites, which was then recyclized using a standard Golden Gate Assembly protocol.

\section{DNA and Protein Sequences:}


Y200C-sfGFP-His6 Protein sequence:

1 MRKGEELFTG VVPILVELDG DVNGHKFSVR GEGEGDATNG KLTLKFICTT GKLPVPWPTL

61 VTTLTYGVQC FARYPDHMKQ HDFFKSAMPE GYVQERTISF KDDGTYKTRA EVKFEGDTLV

386

121 NRIELKGIDF KEDGNILGHK LEYNFNSHNV YITADKQKNG IKANFKIRHN VEDGSVQLAD

181 HYQQNTPIGD GPVLLPDNHC LSTQSVLSKD PNEKRDHMVL LEFVTAAGIT HGMDELYKHH 241 HHHH*

Y200C sfGFP was expressed as previously reported ${ }^{21,23}$

Y200C-sfGFP-His6-RRRRY Protein sequence:

1 MRKGEELFTG VVPILVELDG DVNGHKFSVR GEGEGDATNG KLTLKFICTT GKLPVPWPTL 61 VTTLTYGVQC FARYPDHMKQ HDFFKSAMPE GYVQERTISF KDDGTYKTRA EVKFEGDTLV 121 NRIELKGIDF KEDGNILGHK LEYNFNSHNV YITADKQKNG IKANFKIRHN VEDGSVQLAD 181 HYQQNTPIGD GPVLLPDNHC LSTQSVLSKD PNEKRDHMVL LEFVTAAGIT HGMDELYKHH 241 HHHHRRRRY

Y200C-sfGFP-His6-EEEEY Protein sequence:

1 MRKGEELFTG VVPILVELDG DVNGHKFSVR GEGEGDATNG KLTLKFICTT GKLPVPWPTL 61 VTTLTYGVQC FARYPDHMKQ HDFFKSAMPE GYVQERTISF KDDGTYKTRA EVKFEGDTLV 121 NRIELKGIDF KEDGNILGHK LEYNFNSHNV YITADKQKNG IKANFKIRHN VEDGSVQLAD 181 HYQQNTPIGD GPVLLPDNHC LSTQSVLSKD PNEKRDHMVL LEFVTAAGIT HGMDELYKHH 241 HHHHGGSEEE EY* 
1 ATGTCGAATA AATATCGTGT GCGTAAGAAC GTCTTGCATC TGACGGACAC AGAGAAACGC

61 GACTTTGTTC GCACCGTTCT TATCTTAAAA GAAAAGGGA TTTATGATCG CTACATCGCA

121 TGGCACGGAG CCGCAGGCAA GTTCCACACG CCGCCTGGAA GCGATCGCAA TGCGGCGCAC

181 ATGTCGTCAG CTTTCTTACC ATGGCACCGC GAATATTTAT TGCGTTTTGA CGCGACCTTC

241 AAAGCATTAA CCCCGAGGTC ACACTGCCCT ATTGGGAGTG GGAAACCGAT GCTCAAATGC

301 AAGATCCTCT CAATCTCAGA TTTGGTCCGC AGACTTTATG GGGGGAAACG GTAATCCGAT 361 CAAGGATTTC ATCGTGGACA CGGGACCATT TGCGGCAGGG CGCTGGACCA CGATTGATGA

421 GCAAGGAAAC CCTAGTGGGG GTCTGAAACG TAATTTCGGT GCGACAAAAG AAGCGCCCAC 481 ATTGCCTACT CGTGACGATG TCTTGAACGC ACTTAAAATC ACGCAGTATG ACACGCCGCC 541 GTGGGATATG ACTTCGCAGA ACTCTTTCCG CAATCAGCTG GAAGGCTTTA TTAACGGGCC 601 TCAGCTTCAC AATCGCGTCC ACCGCTGGGT AGGCGGACAA ATGGGTGTTG TGCCCACTGC 661 CCCGAATGAC CCCGTCTTCT TCTTGCATCA TGCTAACGTC GACCGTATCT GGGCCGTCTG 721 GCAGATCATC CACCGCAACC AGAATTACCA ACCGATGAAG AACGGCCCAT TCGGGCAGAA 781 CTTCCGCGAT CCTATGTACC CCTGGAATAC AACACCCGAA GACGTTATGA ATCATCGCAA 841 ATTAGGTTAC GTTTATGACA TCGAACTTCG CAAGAGTAAG CGCTCCTCTc tcgagcacca 901 ccaccaccac cactga

Corresponding to:

1 MSNKYRVRKN VLHLTDTEKR DFVRTVLILK EKGIYDRYIA WHGAAGKFHT PPGSDRNAAH

61 MSSAFLPWHR EYLLRFERDL QSINPEVTLP YWEWETDAQM QDPSQSQIWS ADFMGGNGNP 121 IKDFIVDTGP FAAGRWTTID EQGNPSGGLK RNFGATKEAP TLPTRDDVLN ALKITQYDTP 181 PWDMTSQNSF RNQLEGFING PQLHNRVHRW VGGQMGVVPT APNDPVFFLH HANVDRIWAV 241 WQIIHRNQNY QPMKNGPFGQ NFRDPMYPWN TTPEDVMNHR KLGYVYDIEL RKSKRSSLEH 301 HHHHH* 
1 ATGACCCGTA AAAACGCTAA AGATTTCCTT CCCGACGAGC GCCAACGCTA CTGTAACGCT

61 TTGCTGACAC TGAAGCAGAC GATCGAACCT GGGCACACGT TGAGCAAGTA TGACGAATTT

121 GTAGCTATCC ACTACGGTGT CACCCGCCGC TTACGCAACG GCATTCCAAT CGGAGATGGA 181 GCCCACTTCG TGCCGGGCTT TCTTGCTTGG CATCGTGAGT ATCTGAATCG CTTTGAGAAG 241 GCAATTCGCA CAGTGGACAG TACCTTATCA CTGCCTTACT GGAATTGGTC TAGTGGTGAT 301 GATACAGATA CGACCGAGAT CTTCACAGAC GATTTTATGG GACCCCCGGG AGATCCGAAC 361 AATGGCAACA AAATTACATC CGGCTATTTC GTAGAGAATA ACTGGGAGGT TCACTCTGAG 421 CTGGACGGCG GGAACAATGG TTCGGTTCTT GTCCGTGACT CCACACTGTT ATCTTCATCA 481 AAGTTATCTC AGGTCTCGGG TTACGGCGAA TTGGCTATGG ATGCCGTAAA TGGTGATAAC 541 GACTTCGACT CATTTCTGCC TGGCTTAGAG GGTCCACATG GTTCCATCCA CATGTGGATC 601 GGTGGACATA TGACCAGTAT GACCAGTCCC AACGATCCTA TTTTCTTCCT TCATCACGCC 661 AATATTGATC GTTTGTGGAG TAAGTGGCAA GAGTTGCATC CTGGGCCGGA GAACTATAAT 721 CCAAACAACG ACGGTTCATA TGGCAGTCGC CTTAATGACC GTATGTGGCC GTGGGACGGC 781 TCCGAGGACA CCACAACTAC ACGCACCGGA ACCGCAACAG GGATCTCTCT GCAAGGTTTA 841 CTTCCTACCT TTAGTGATTA TGATATTGTA ACACCGCGCC ATGTGCTTGA TAACAATTTG 901 ACGATTCCGC ACCACCATCA CCACCATTAA 301 TIPHHHHHH*

Corresponding to:

1 MTRKNAKDFL PDERQRYCNA LLTLKQTIEP GHTLSKYDEF VAIHYGVTRR LRNGIPIGDG 61 AHFVPGFLAW HREYLNRFEK AIRTVDSTLS LPYWNWSSGD DTDTTEIFTD DFMGPPGDPN 121 NGNKITSGYF VENNWEVHSE LDGGNNGSVL VRDSTLLSSS KLSQVSGYGE LAMDAVNGDN 181 DFDSFLPGLE GPHGSIHMWI GGHMTSMTSP NDPIFFLHHA NIDRLWSKWQ ELHPGPENYN 241 PNNDGSYGSR LNDRMWPWDG SEDTTTTRTG TATGISLQGL LPTFSDYDIV TPRHVLDNNL 
MYGGS His6 NanoLuciferase

1 ATGTATGGTG GTTCACACCA TCACCATcac catGTCTTCA CACTCGAAGA TTTCGTTGGG

61 GACTGGCGAC AGACAGCCGG CTACAACCTG GACCAAGTCC TTGAACAGGG AGGTGTGTCC

121 AGTTTGTTTC AGAATCTCGG GGTGTCCGTA ACTCCGATCC AAAGGATTGT CCTGAGCGGT

181 GAAAATGGGC TGAAGATCGA CATCCATGTC ATCATCCCGT ATGAAGGTCT GAGCGGCGAC

241 CAAATGGGCC AGATCGAAAA AATTTTTAAG GTGGTGTACC CTGTGGATGA TCATCACTTT 301 AAGGTGATCC TGCACTATGG CACACTGGTA ATCGACGGGG TTACGCCGAA CATGATCGAC 361 TATTTCGGAC GGCCGTATGA AGGCATCGCC GTGTTCGACG GCAAAAAGAT CACTGTAACA 421 GGGACCCTGT GGAACGGCAA CAAAATTATC GACGAGCGCC TGATCAACCC CGACGGCTCC 481 CTGCTGTTCC GAGTAACCAT CAACGGAGTG ACCGGCTGGC GGCTGTGCGA ACGCATTCTG

413

414

415

417 541 GCGTAA

Corresponding to:

1 MYGGSHHHHH HVFTLEDFVG DWRQTAGYNL DQVLEQGGVS SLFQNLGVSV TPIQRIVLSG 61 ENGLKIDIHV IIPYEGLSGD QMGQIEKIFK VVYPVDDHHF KVILHYGTLV IDGVTPNMID 121 YFGRPYEGIA VFDGKKITVT GTLWNGNKII DERLINPDGS LLFRVTINGV TGWRLCERIL $181 \mathrm{~A} *$ 
A

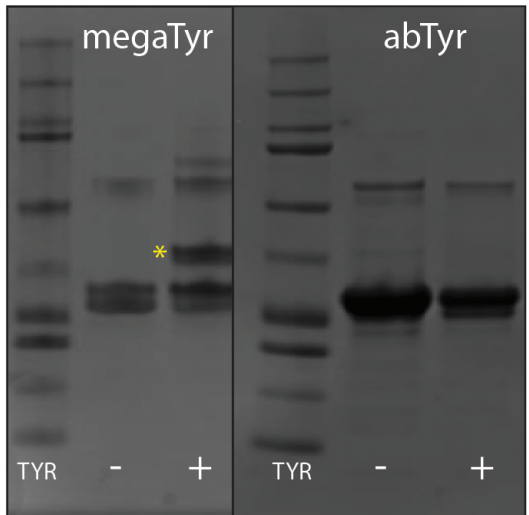

B

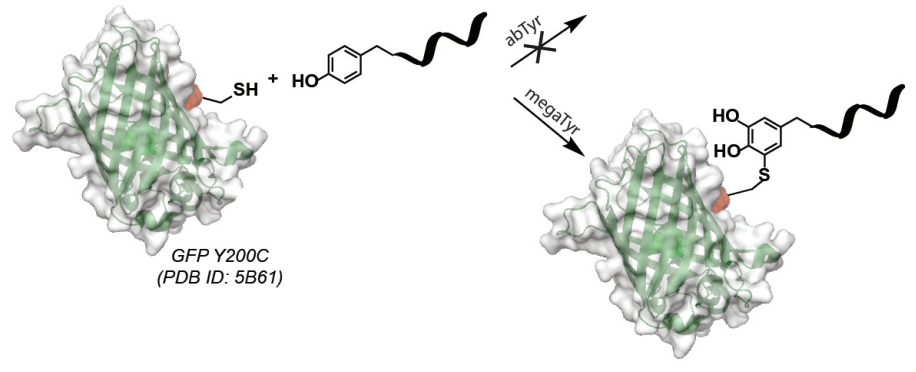

Figure S1: SDS-PAGE Gel analysis of DNA-GFP constructs. A) SDS-PAGE Gel analysis of tyrosinase activity towards phenol-DNA. B) Reaction scheme indicating the tyrosinase mediated coupling of phenol-DNA to Y200C GFP

\section{abTYR paF}

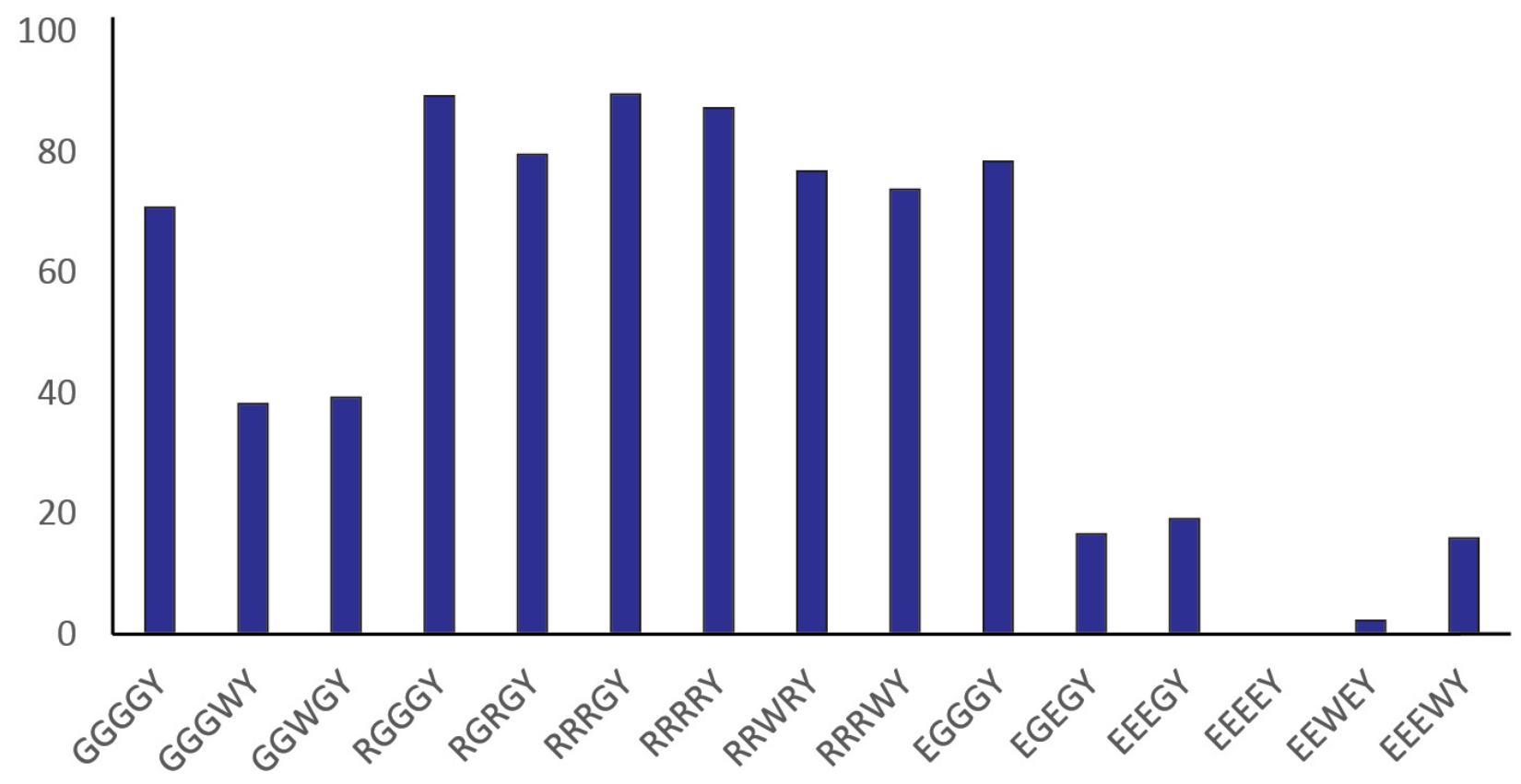

Figure S2: paF-MS2-peptide screen of abTYR substrate preferences. $50 \mu \mathrm{M}$ paF-MS2, 250 $\mu \mathrm{M}$ peptide, $12 \mathrm{U} / \mathrm{L}$ abTYR, $30 \mathrm{~min}$ at room temperature. 
A

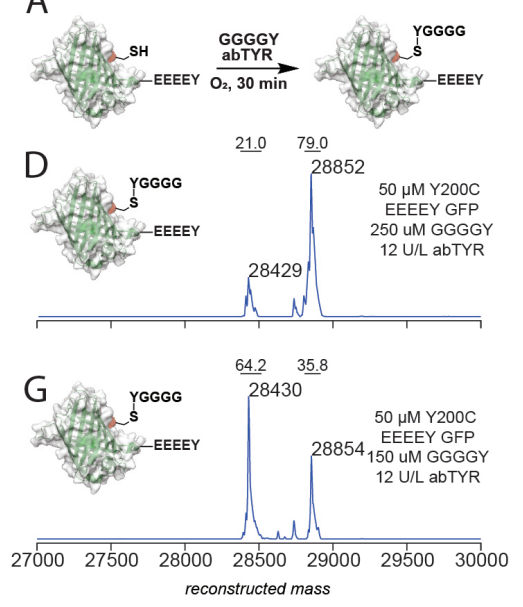

B
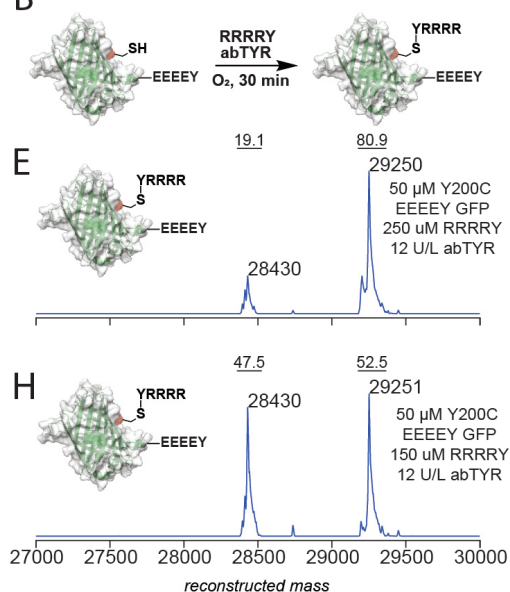

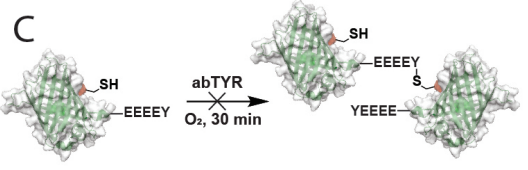

$\mathrm{F}$
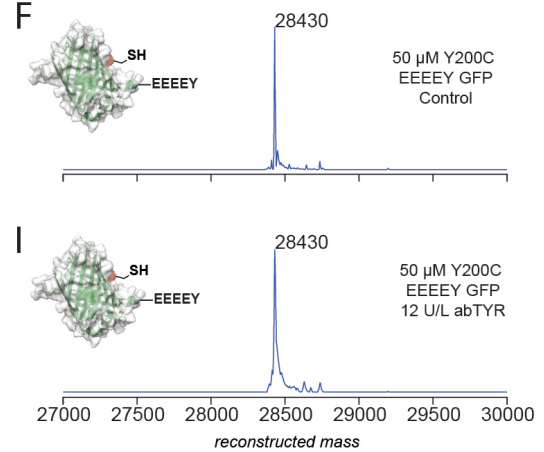

Figure S3: Selective activation of tyrosines on proteins and peptides with abTYR. A-C) Reaction schemes depicting the reaction of EEEEY Y200C GFP with GGGGY and RRRRY peptides, along with a control reaction without peptide. D-E) abTYR (12 U/L) catalyzed reactions of EEEEY Y200C GFP with $250 \mu \mathrm{M}$ GGGGY or RRRRY peptide. F) EEEEY Y200C GFP negative control. G-H) abTYR (12 U/L) catalyzed reactions of EEEEY Y200C GFP with $150 \mu \mathrm{M}$ GGGGY or RRRRY peptide. I) EEEEY Y200C GFP exposed to $12 \mathrm{U} / \mathrm{L}$ of abTYR for $30 \mathrm{~min}$ in the absence of peptide.
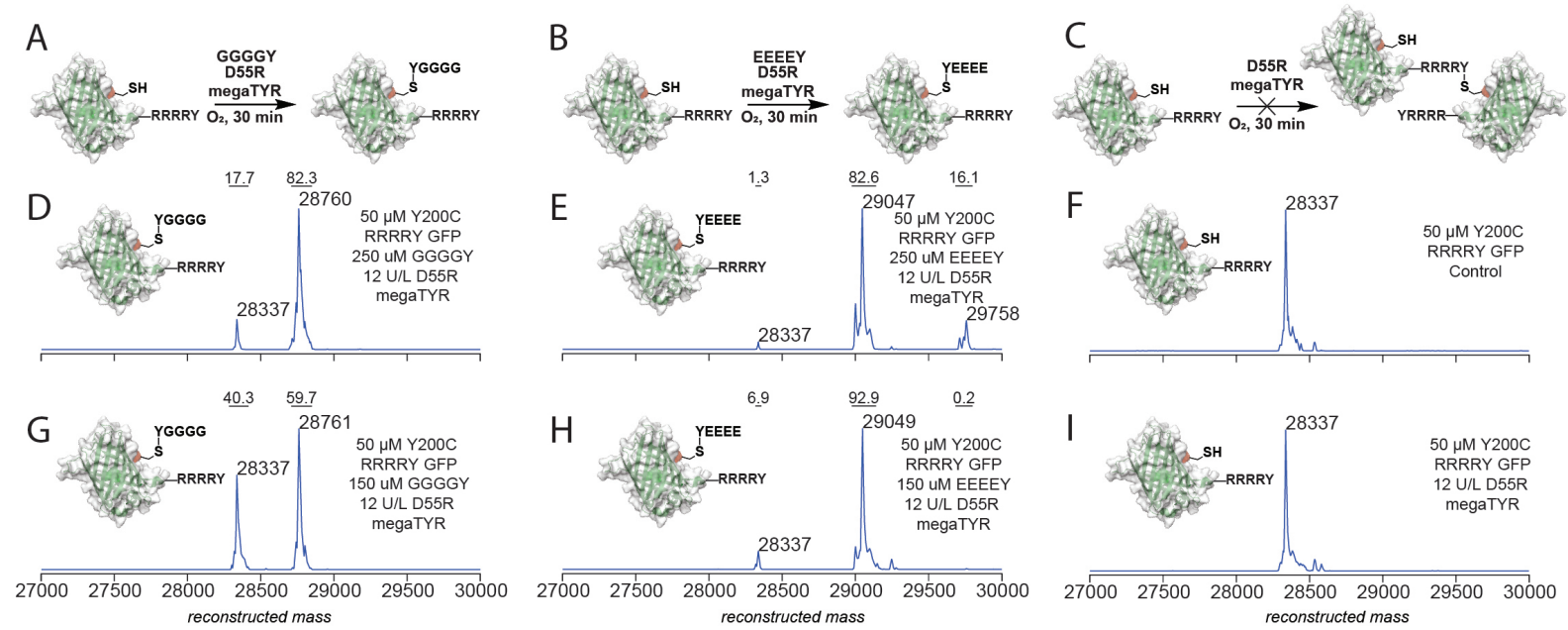

Figure S4: Selective activation of tyrosines on proteins and peptides with D55R megaTYR. A-C) Reaction schemes depicting the reaction of RRRRY Y200C GFP with GGGGY and EEEEY peptides, along with a control reaction without peptide. D-E) D55R megaTYR (12 U/L) catalyzed reactions of RRRRY Y200C GFP with $250 \mu \mathrm{M}$ GGGGY or EEEEY peptide. F) RRRRY Y200C GFP negative control. G-H) D55R megaTYR (12 U/L) catalyzed reactions of RRRRY Y200C GFP with $150 \mu \mathrm{M}$ GGGGY or EEEEY peptide. I) RRRRY Y200C GFP exposed to $12 \mathrm{U} / \mathrm{L}$ of D55R megaTYR for $30 \mathrm{~min}$ in the absence of peptide. 

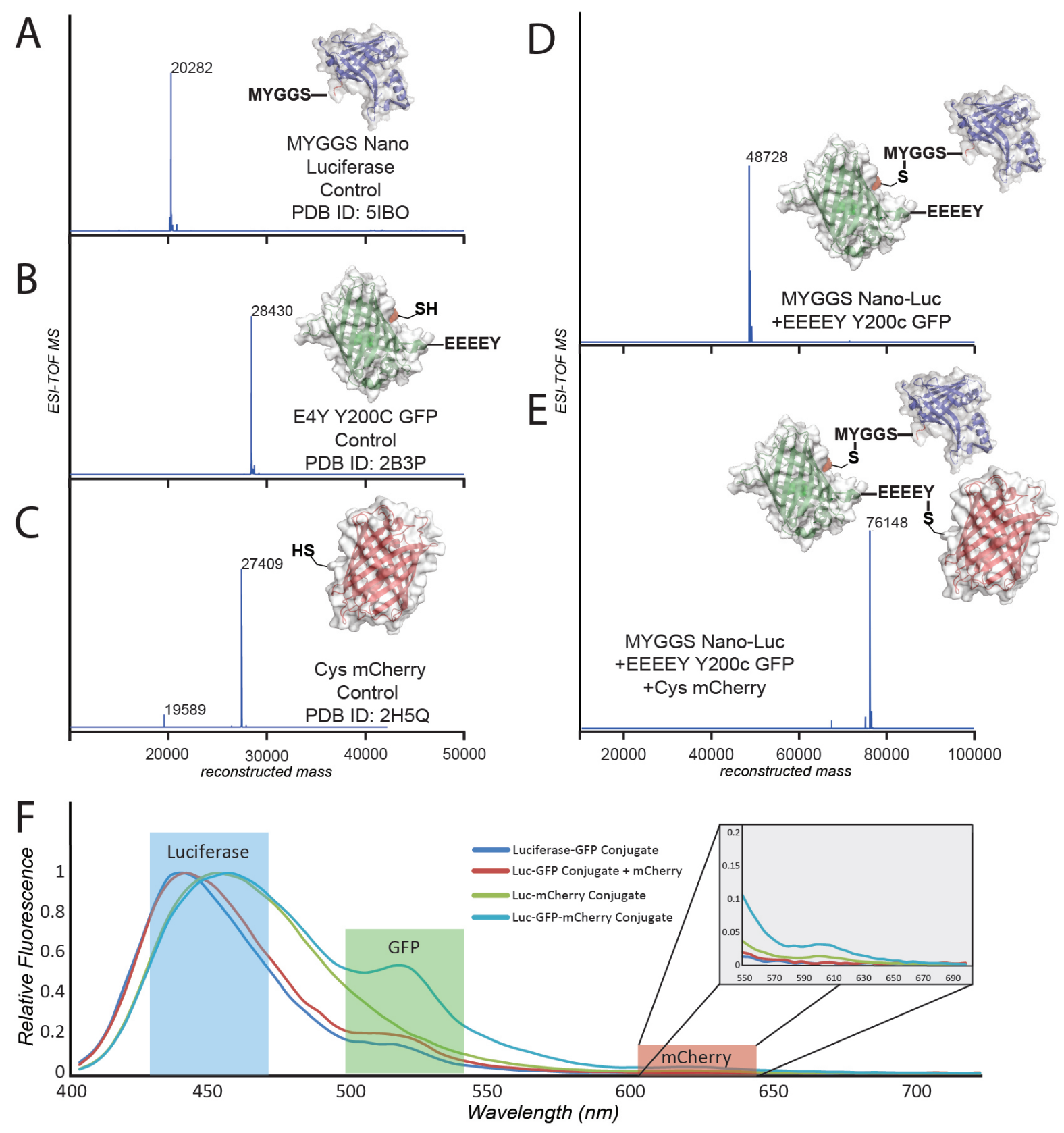

Figure S5: Supplemental data for figure 6. A-C) MYGGS nano-luciferase, EEEEY Y200C GFP, and S152C mCherry negative controls D-E) Dimeric and trimeric protein constructs made by taking advantage of native and engineered charge preferences of tyrosinases F) Fluorescence analysis confirming the proximity FRET triplet of luciferase, GFP and mCherry. 
Representative Spectra

Figure 1D

A
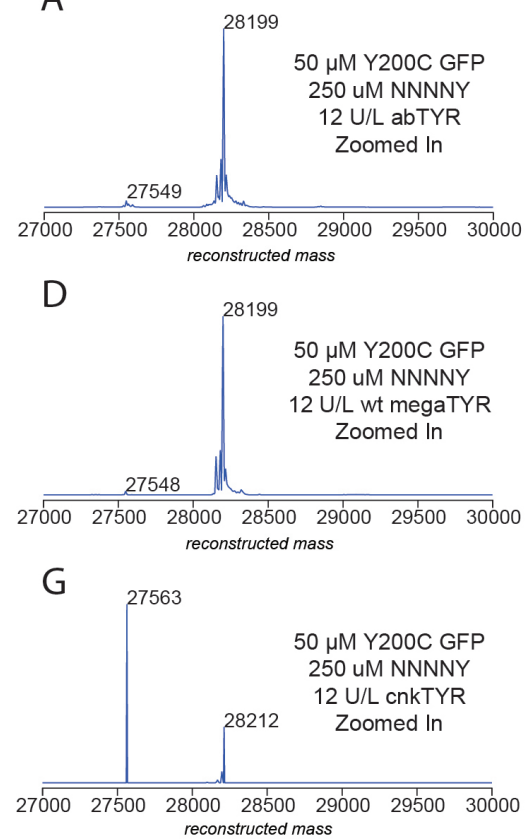

B

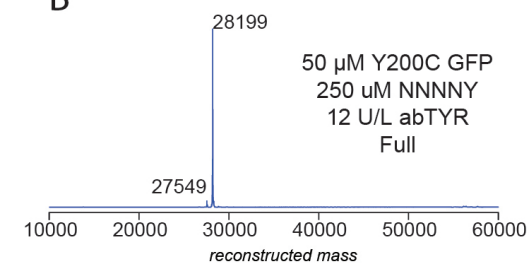

$E$

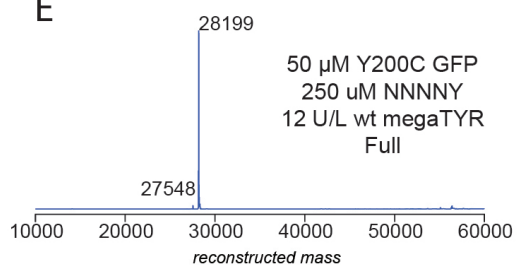

$\mathrm{H}$

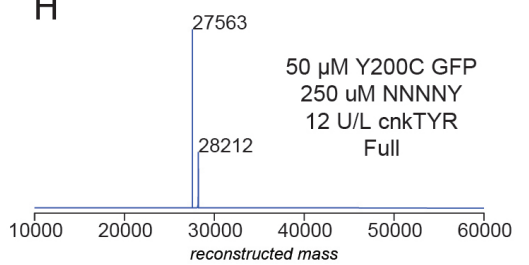

$\mathrm{C}$

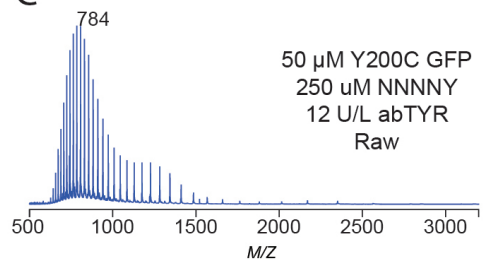

$\mathrm{F}$

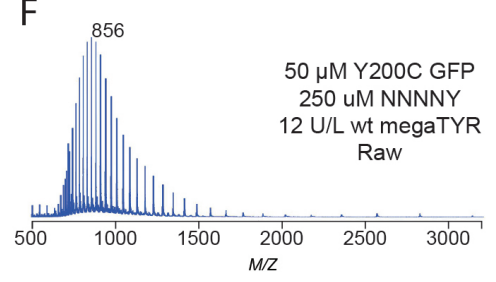

I

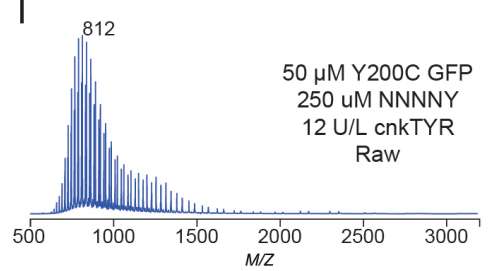

Figure S6: Representitive spectra for figure 1D A-C) Deconvoluted and raw mass spectra for the product of the abTYR catalyzed reaction of Y200C GFP and NNNNY peptide D-F) Deconvoluted and raw mass spectra for the product of the wild type megaTYR catalyzed reaction of Y200C GFP and NNNNY peptide. G-I) Deconvoluted and raw mass spectra for the product of the cnkTYR catalyzed reaction of Y200C GFP and NNNNY peptide. 
Representative Spectra

Figure $4 B$ and $4 C$
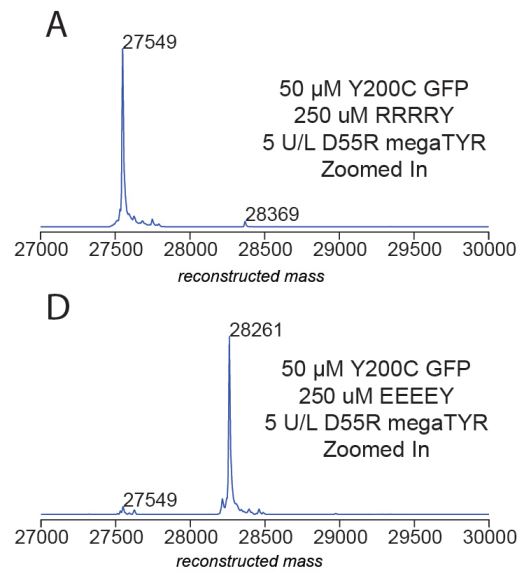

G

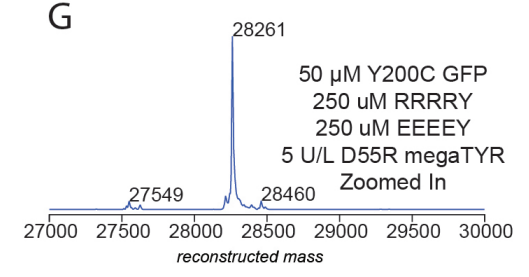

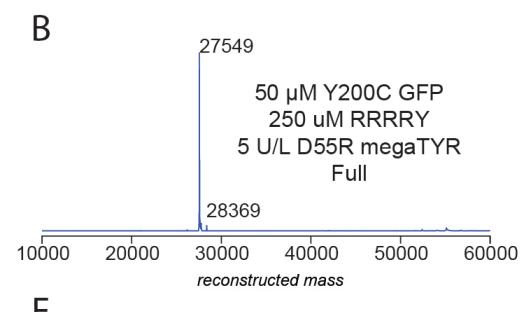
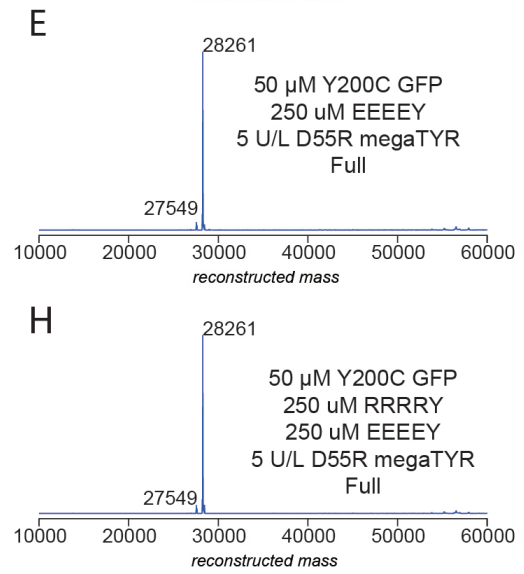
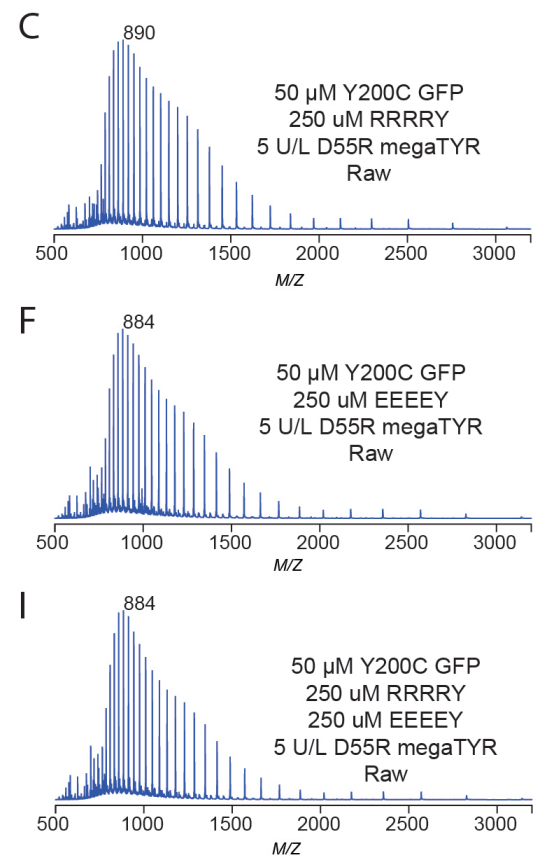

Figure S7: Representitive spectra for figure $4 \mathrm{~B}$ and $4 \mathrm{C}$ A-C) Deconvoluted and raw mass spectra for the product of the megaTYR catalyzed reaction of Y200C GFP and RRRRY peptide D-F) Deconvoluted and raw mass spectra for the product of the D55R megaTYR catalyzed reaction of Y200C GFP and EEEEY peptide. G-I) Deconvoluted and raw mass spectra for D55R megaTYR EEEEY vs. RRRRY competition assay. 
Representative Spectra

Figure 4D

A

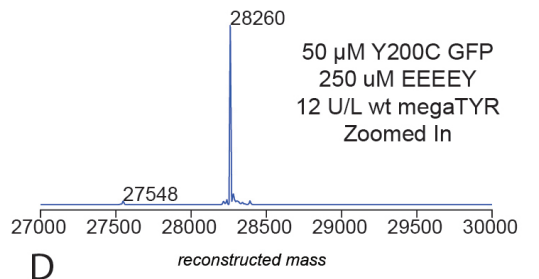

D reconstructed mass

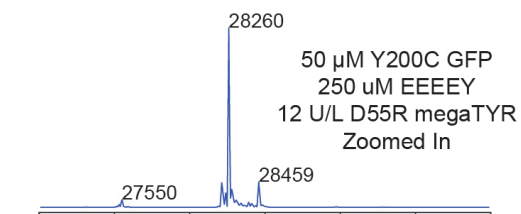

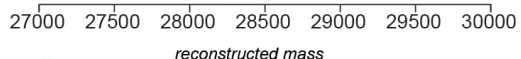

G

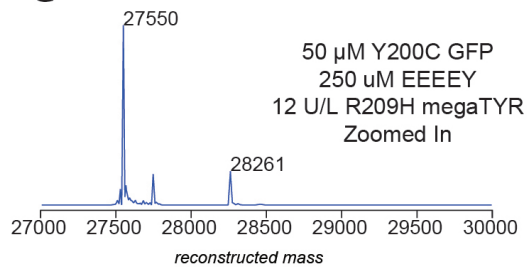

B

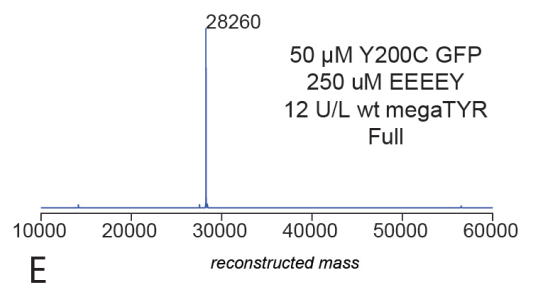

E
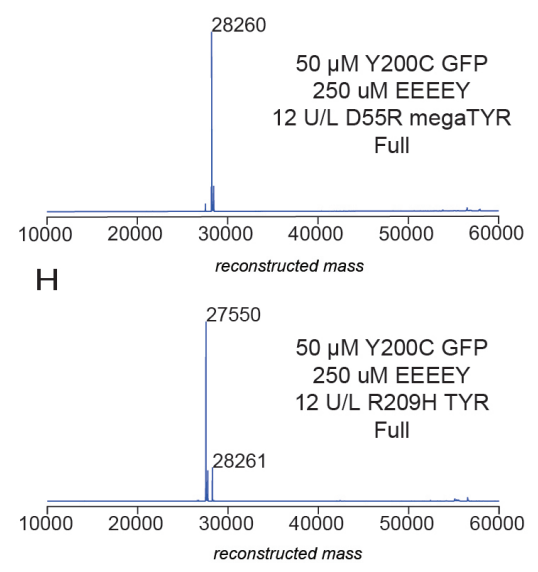

C

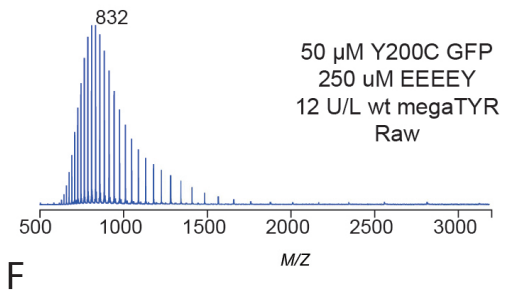

$\mathrm{F}$
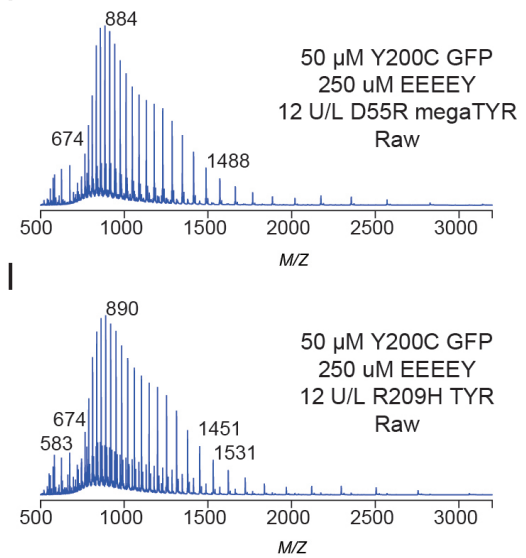

Figure S8: Representitive spectra for figure 4D A-C) Deconvoluted and raw mass spectra for the product of the wild type megaTYR catalyzed reaction of Y200C GFP and EEEEY peptide D-F) Deconvoluted and raw mass spectra for the product of the D55R megaTYR catalyzed reaction of Y200C GFP and EEEEY peptide. G-I) Deconvoluted and raw mass spectra for the product of the R209H megaTYR catalyzed reaction of Y200C GFP and EEEEY peptide. 


\section{A}

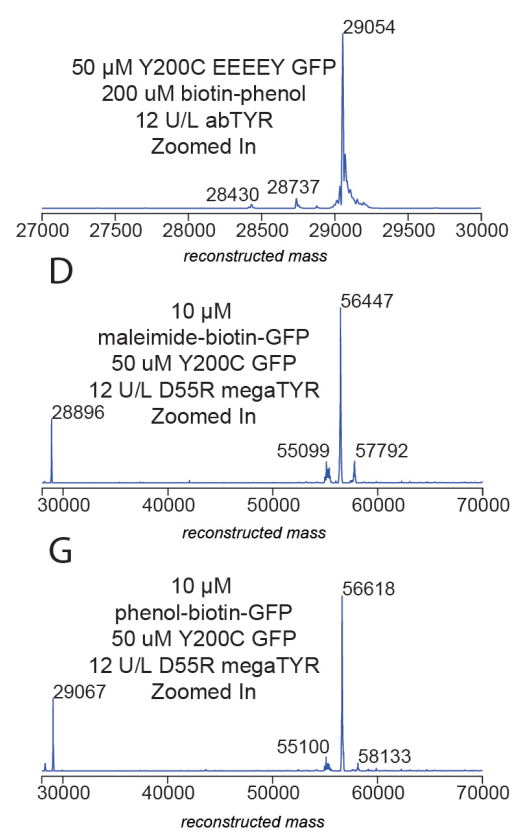

Representative Spectra

Figure 5
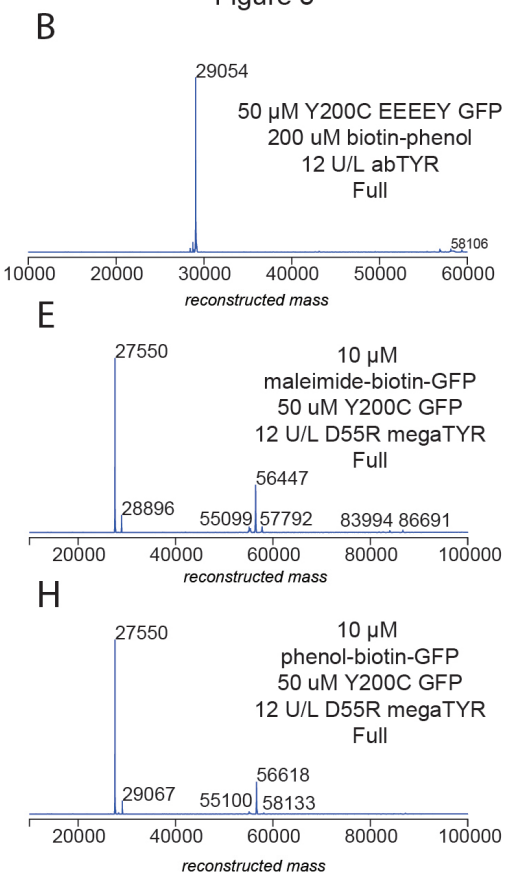
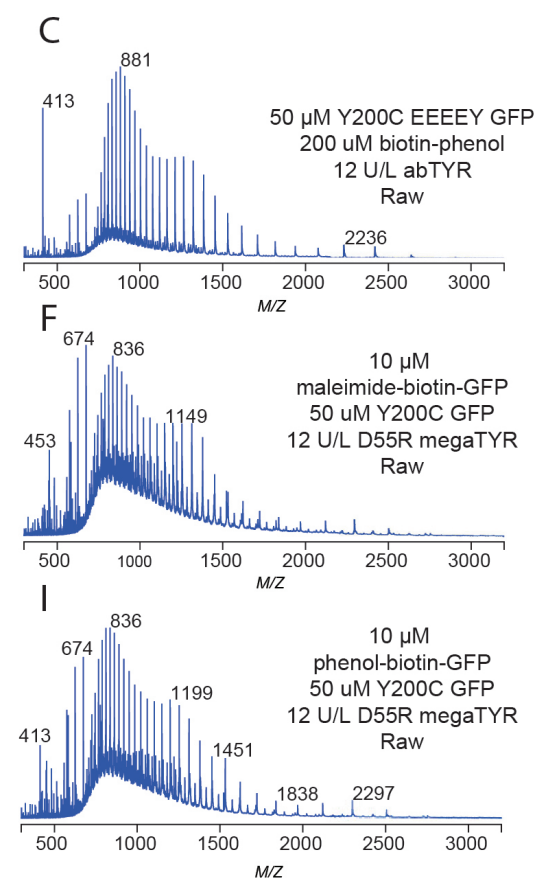

Figure S9: Representitive spectra for figure $5 \mathrm{~A}-\mathrm{C}$ ) Deconvoluted and raw mass spectra for the product of the abTYR catalyzed reaction of EEEEY Y200C GFP and phenol-biotin D-F) Deconvoluted and raw mass spectra for the product of the D55R megaTYR catalyzed reaction of maleimide-biotin EEEEY-GFP and Y200C GFP peptide. G-I) Deconvoluted and raw mass spectra for the product of the D55R megaTYR catalyzed reaction of phenol-biotin EEEEY-GFP and Y200C GFP. 
Representative Spectra

Figure 6

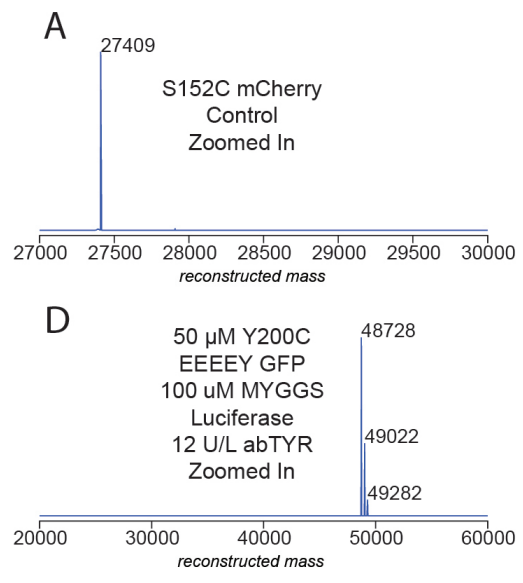

G

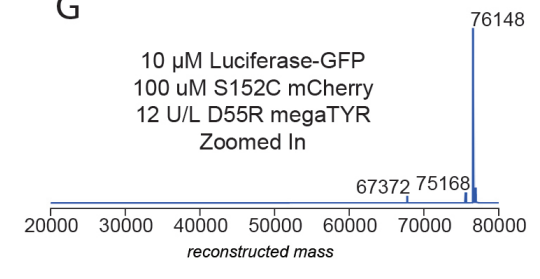

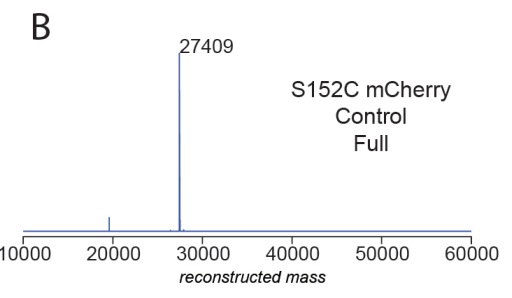
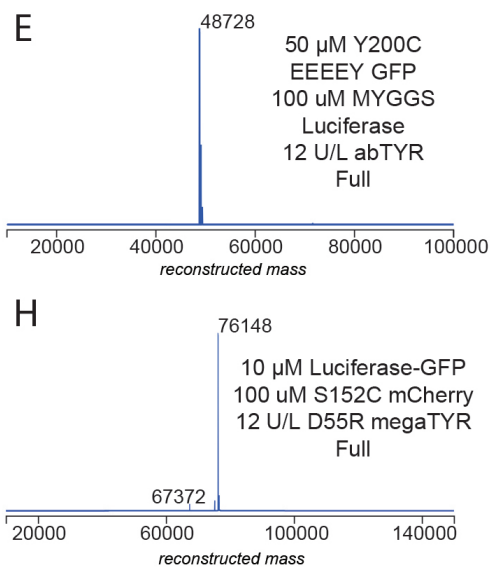
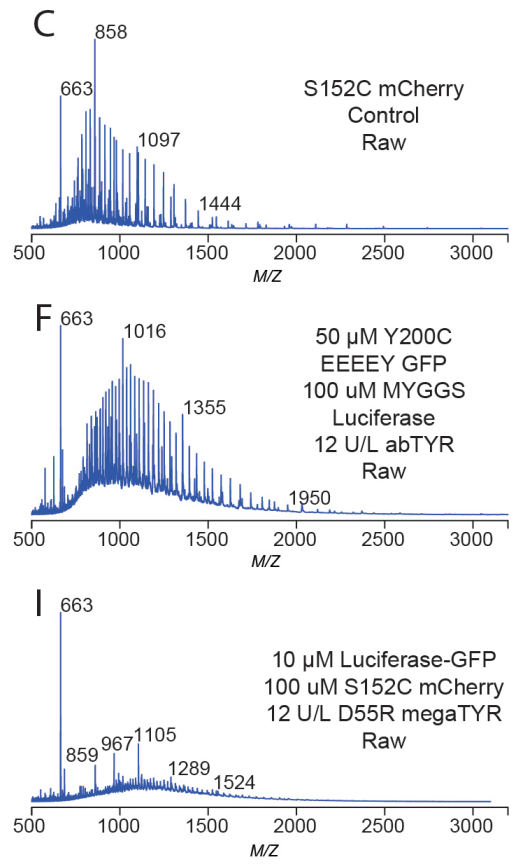

Figure S10: Representitive spectra for figure 6 A-C) Deconvoluted and raw mass spectra for the S152C mCherry control D-F) Deconvoluted and raw mass spectra for the product of the abTYR catalyzed reaction of EEEEY Y200C GFP and MYGGS nano luciferase. GI) Deconvoluted and raw mass spectra for the product of the D55R megaTYR catalyzed reaction of the luciferase-GFP-EEEEY coupling product and S152C mCherry. 
Representative Spectra

Figure $\mathbf{3} 3$
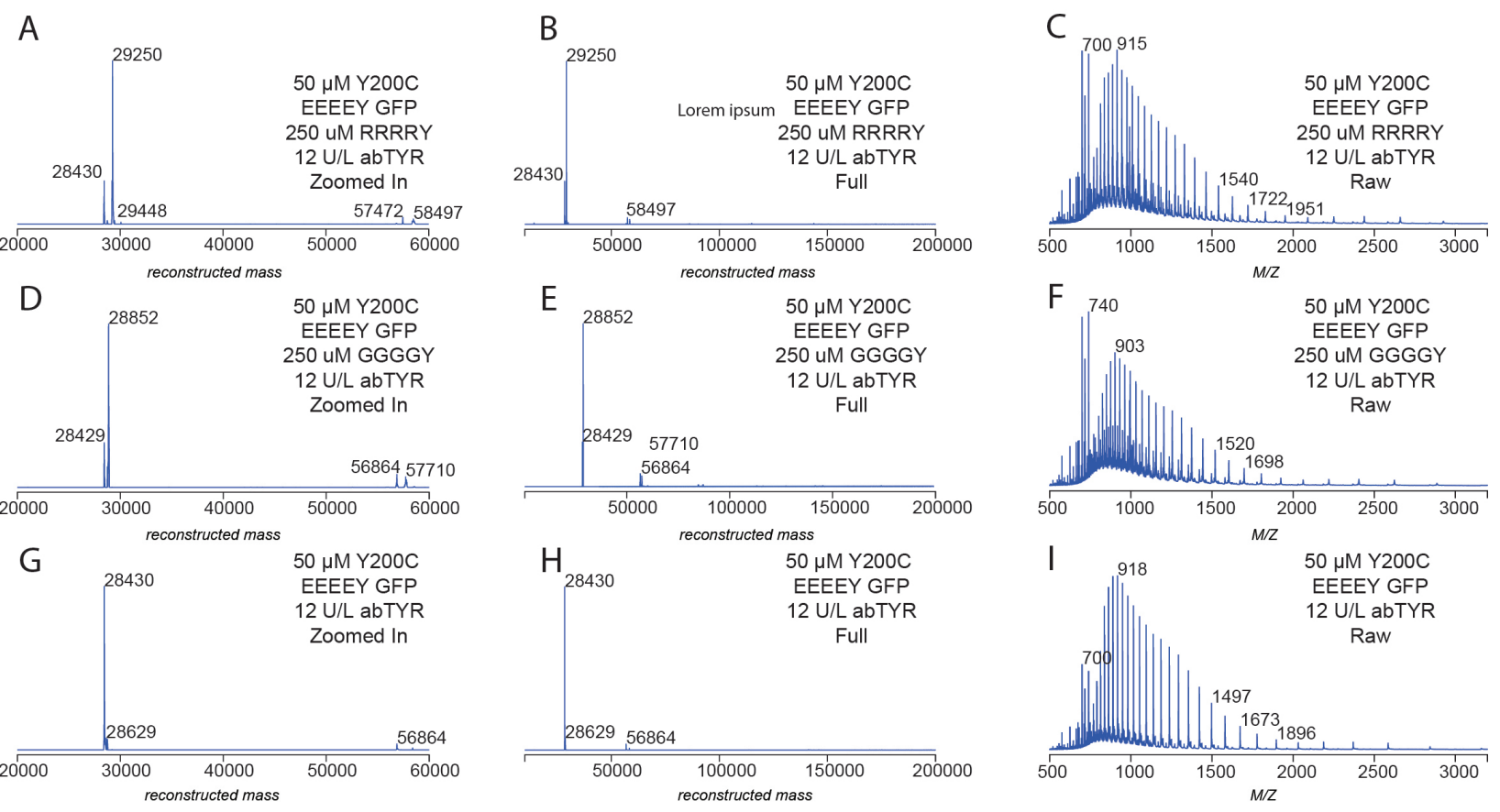

Figure S11: Representitive spectra for figure S3 A-C) Deconvoluted and raw mass spectra for the product abTYR catalyzed reaction between EEEEY Y200C GFP and RRRRY peptide D-F) Deconvoluted and raw mass spectra for the product of the abTYR catalyzed reaction of EEEEY Y200C GFP and GGGGY peptide. G-I) Deconvoluted and raw mass spectra for the product of the reaction between abTYR and EEEEY Y200C GFP. 
Representative Spectra

Figure $\mathrm{S} 4$

A
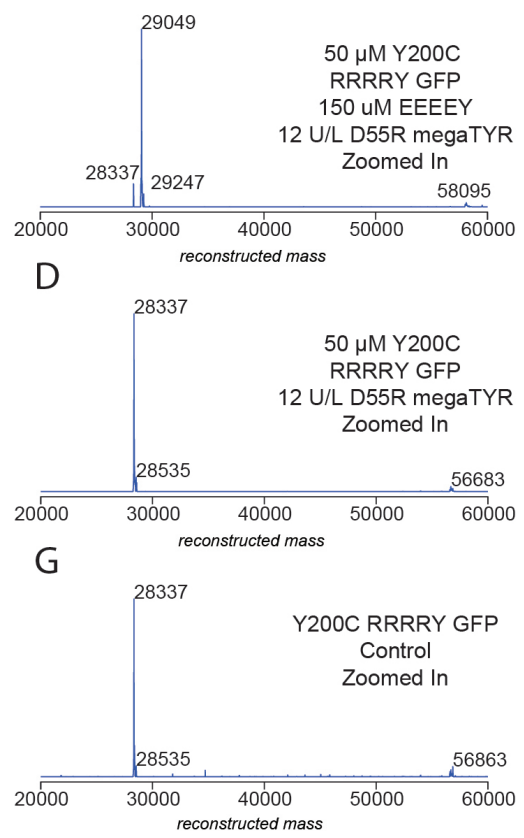

B

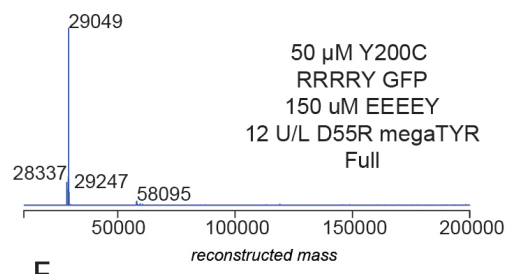

$\mathrm{E}$
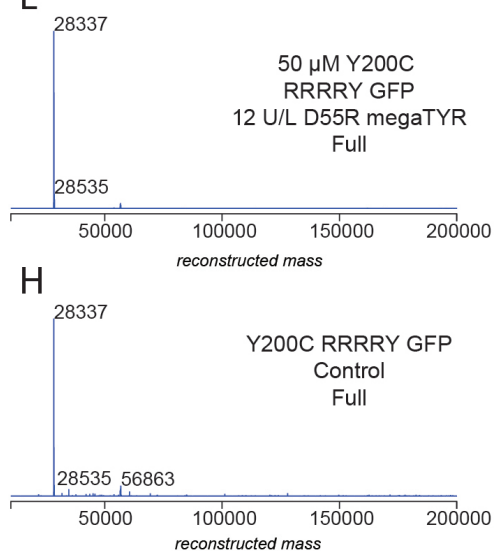

C

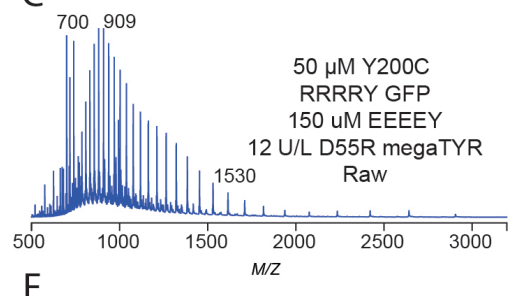

$\mathrm{F}$

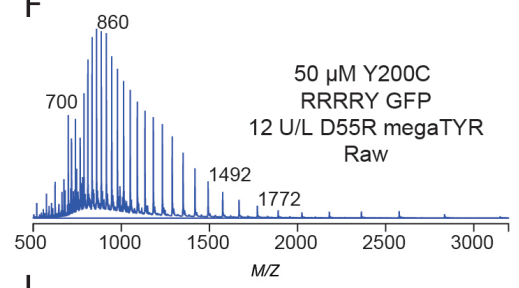

।

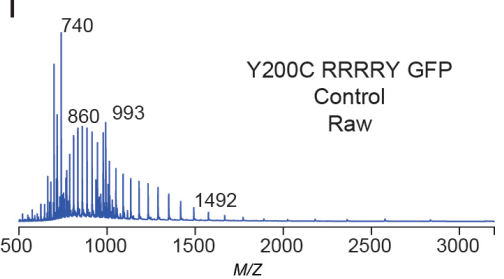

Figure S12: Representitive spectra for figure S4 A-C) Deconvoluted and raw mass spectra for the product D55R megaTYR catalyzed reaction between RRRRY Y200C GFP and EEEEY peptide D-F) Deconvoluted and raw mass spectra for the product of the reaction between D55R megaTYR and RRRRY Y200C GFP. G-I) Deconvoluted and raw mass spectra for the RRRRY Y200C GFP control. 


\section{Supporting Tables}

Table S1: Calculated masses of peptides used in this study

\begin{tabular}{|c|c|}
\hline Peptide & Mass (Da) \\
\hline GGGGY & 409.4 \\
NNGGY & 523.5 \\
NNNNY & 637.6 \\
GGGWY & 538.6 \\
GGWGY & 538.6 \\
RGGGY & 508.5 \\
RGRGY & 607.7 \\
RRGGY & 607.7 \\
RRRGY & 706.8 \\
RRRRY & 805.9 \\
RRRWY & 836.0 \\
RRWRY & 836.0 \\
EGGGY & 481.5 \\
EGEGY & 553.5 \\
EEGGY & 553.5 \\
EEEGY & 625.6 \\
EEEEY & 697.7 \\
EEEWY & 754.8 \\
EEWEY & 754.8 \\
\hline
\end{tabular}


Table S2: Calculated Potentials of Homology-Based Mutants

\begin{tabular}{|c|c|c|c|c|c|c|c|}
\hline Protein & Variant & $\begin{array}{c}\text { Electrostatic } \\
\text { Energy } \\
\text { w/ Lithium } \\
(\mathrm{kJ} / \mathrm{mol})\end{array}$ & $\begin{array}{c}\text { Electrostatic } \\
\text { Energy } \\
\text { w/o Lithium } \\
(\mathrm{kJ} / \mathrm{mol})\end{array}$ & $\begin{array}{c}\Delta \mathrm{E} \\
(\mathrm{kJ} / \mathrm{mol})\end{array}$ & $\begin{array}{l}\Delta \mathrm{V} \\
(\mathrm{V})\end{array}$ & $\begin{array}{c}\Delta \Delta \mathrm{V} \\
(\mathrm{V})\end{array}$ & $\begin{array}{c}\text { Conservation } \\
\text { Score }\end{array}$ \\
\hline \multirow[t]{2}{*}{ abTYR } & Full & -309319 & -307805 & -1515 & -15.7 & $\mathrm{~N} / \mathrm{A}$ & $\mathrm{NA}$ \\
\hline & Subunit & -59746 & -59318 & -428 & -4.4 & $\mathrm{~N} / \mathrm{A}$ & NA \\
\hline \multirow[t]{25}{*}{ megaTYR } & wt & -47096 & -47521 & 426 & 4.4 & $\mathrm{~N} / \mathrm{A}$ & NA \\
\hline & D16K & -46248 & -46743 & 495 & 5.1 & 0.7 & 1 \\
\hline & D21K & -45541 & -46034 & 493 & 5.1 & 0.7 & 5 \\
\hline & E31K & -46023 & -46524 & 501 & 5.2 & 0.8 & 5 \\
\hline & D55K & -45707 & -46414 & 707 & 7.3 & 2.9 & 3 \\
\hline & D55R & -45928 & -46651 & 723 & 7.5 & 3.1 & 3 \\
\hline & E71K & -45099 & -45626 & 526 & 5.5 & 1.0 & 5 \\
\hline & D79K & -45406 & -45921 & 515 & 5.3 & 0.9 & 5 \\
\hline & E86K & -46072 & -46562 & 490 & 5.1 & 0.7 & 2 \\
\hline & D102K & -46218 & -46742 & 524 & 5.4 & 1.0 & 5 \\
\hline & D123K & -46225 & -46758 & 533 & 5.5 & 1.1 & 1 \\
\hline & D127K & -45648 & -46163 & 515 & 5.3 & 0.9 & 3 \\
\hline & D140K & -45954 & -46524 & 571 & 5.9 & 1.5 & 1 \\
\hline & E141K & -45698 & -46310 & 612 & 6.3 & 1.9 & 2 \\
\hline & E158K & -44989 & -45614 & 626 & 6.5 & 2.1 & 1 \\
\hline & D166K & -45737 & -46250 & 513 & 5.3 & 0.9 & 1 \\
\hline & D167K & -45808 & -46349 & 541 & 5.6 & 1.2 & 5 \\
\hline & D183K & -45796 & -46420 & 624 & 6.5 & 2.1 & 6 \\
\hline & E274K & -45300 & -45810 & 510 & 5.3 & 0.9 & 2 \\
\hline & D275K & -45833 & -46348 & 515 & 5.3 & 0.9 & 4 \\
\hline & E289K & -44505 & -45015 & 509 & 5.3 & 0.9 & 6 \\
\hline & $\mathrm{R} 209 \mathrm{H}$ & -47419 & -47713 & 294 & 3.0 & -1.4 & 6 \\
\hline & R209E & -47882 & -48051 & 170 & 1.8 & -2.7 & 6 \\
\hline & $\mathrm{R} 280 \mathrm{H}$ & -47547 & -47935 & 388 & 4.0 & -0.4 & 2 \\
\hline & $\mathrm{R} 280 \mathrm{E}$ & -48290 & -48640 & 350 & 3.6 & -0.8 & 2 \\
\hline
\end{tabular}


Table S3: Calculated Potentials of Proximity-Based Mutants

\begin{tabular}{|c|c|c|c|c|c|c|c|}
\hline Protein & Variant & $\begin{array}{c}\text { Electrostatic } \\
\text { Energy } \\
\text { w/ Lithium } \\
(\mathrm{kJ} / \mathrm{mol})\end{array}$ & $\begin{array}{c}\text { Electrostatic } \\
\text { Energy } \\
\text { w/ Lithium } \\
(\mathrm{kJ} / \mathrm{mol})\end{array}$ & $\begin{array}{c}\Delta \mathrm{E} \\
(\mathrm{kJ} / \mathrm{mol})\end{array}$ & $\begin{array}{c}\Delta \mathrm{V} \\
(\mathrm{V})\end{array}$ & $\begin{array}{c}\Delta \Delta \mathrm{V} \\
(\mathrm{V})\end{array}$ & $\begin{array}{c}\text { Conservation } \\
\text { Score }\end{array}$ \\
\hline abTYR & Full & -309319 & -307805 & -1515 & -15.7 & NA & NA \\
& Subunit & -59746 & -59318 & -428 & -4.4 & NA & NA \\
\hline megaTYR & $\mathrm{wt}$ & -47096 & -47521 & 426 & 4.4 & NA & NA \\
& S54K & -46867 & -46340 & 527 & 5.5 & 1.1 & 1 \\
& D55K & -46219 & -45512 & 707 & 7.3 & 2.9 & 3 \\
& D55R & -46453 & -45730 & 723 & 7.5 & 3.1 & 3 \\
& N57K & -46950 & -46540 & 410 & 4.2 & -0.2 & 8 \\
& D123K & -46577 & -46044 & 533 & 5.5 & 1.1 & 1 \\
& D140K & -46330 & -45759 & 571 & 5.9 & 1.5 & 1 \\
& E141K & -46124 & -45513 & 611 & 6.3 & 1.9 & 2 \\
& T156K & -47324 & -46895 & 428 & 4.4 & 0.0 & 1 \\
& E158K & -44989 & -45614 & 626 & 6.5 & 2.1 & 1 \\
& D183K & -45796 & -46420 & 624 & 6.5 & 2.1 & 6 \\
& Q187K & -46830 & -46343 & 488 & 5.1 & 0.6 & 1 \\
R209H & -47419 & -47713 & 294 & 3.0 & -1.4 & 6 \\
& Q214K & -47162 & -46738 & 424 & 4.4 & 0.0 & 2 \\
& T220K & -46976 & -46457 & 519 & 5.4 & 1.0 & 5 \\
\hline
\end{tabular}

Table S4: Calculated Masses of expressed proteins

\begin{tabular}{|c|c|c|c|}
\hline Protein & Modification & Unmodified Mass (Da) & Methionine Excision Mass (Da) \\
\hline Y200C GFP & None & $27,549.0$ & N/A \\
& RRRRY tag & $28,337.0$ & N/A \\
& GGSEEEEY tag & $28,429.9$ & N/A \\
\hline paF MS2 & None & $13,789.0$ & N/A \\
\hline megaTYR & Wild Type & $35,474.8$ & $35,343.6$ \\
& R209H & $35,455.8$ & $35,324.6$ \\
& D55K & $35,487.9$ & $35,356.7$ \\
& D55R & $35,515.9$ & $35,384.7$ \\
\hline
\end{tabular}


Table S5: Calculated masses of Y200C GFP oxidative coupling products

\begin{tabular}{|c|c|c|}
\hline Peptide Coupling Partner & Single Addition Mass (Da) & Double Addition Mass (Da) \\
\hline None & $27,549.0$ & N/A \\
GGGGY & $27,974.4$ & $28,399.8$ \\
NNGGY & $28,088.5$ & $28,628.0$ \\
NNNNY & $28,202.6$ & $28,856.2$ \\
GGGWY & $28,103.6$ & $28,658.2$ \\
GGWGY & $28,103.6$ & $28,658.2$ \\
RGGGY & $28,073.6$ & $28,598.0$ \\
RGRGY & $28,172.7$ & $28,796.4$ \\
RRGGY & $28,172.7$ & $28,796.4$ \\
RRRGY & $28,271.8$ & $28,994.6$ \\
RRRRY & $28,370.9$ & $29,192.8$ \\
RRRWY & $28,401.0$ & $29,252.9$ \\
RRWRY & $28,401.0$ & $29,252.9$ \\
EGGGY & $28,046.5$ & $28,543.9$ \\
EGEGY & $28,118.5$ & $28,688.1$ \\
EEGGY & $28,118.5$ & $28,688.1$ \\
EEEGY & $28,190.6$ & $28,832.2$ \\
EEEEY & $28,262.7$ & $28,976.3$ \\
EEEWY & $28,319.8$ & $29,090.6$ \\
EEWEY & $28,319.8$ & $29,090.6$ \\
\hline
\end{tabular}


Table S6: Calculated masses of paF MS2 oxidative coupling products

\begin{tabular}{|c|c|c|}
\hline Peptide Added & Single Addition Mass (Da) & Double Addition Mass (Da) \\
\hline None & $13,789.00$ & N/A \\
GGGGY & $14,214.4$ & $14,639.8$ \\
NNGGY & $14,328.5$ & $14,868.0$ \\
NNNNY & $14,442.6$ & $15,096.2$ \\
GGGWY & $14,343.6$ & $14,898.2$ \\
GGWGY & $14,343.6$ & $14,898.2$ \\
RGGGY & $14,313.5$ & $14,838.0$ \\
RGRGY & $14,412.7$ & $14,036.4$ \\
RRGGY & $14,412.7$ & $14,036.4$ \\
RRRGY & $14,511.8$ & $15,234.6$ \\
RRRRY & $14,610.8$ & $15,432.8$ \\
RRRWY & $14,641.0$ & $15,493.0$ \\
RRWRY & $14,641.0$ & $15,493.0$ \\
EGGGY & $14,286.5$ & $14,784.0$ \\
EGEGY & $14,358.5$ & $14,928.0$ \\
EEGGY & $14,358.5$ & $14,928.0$ \\
EEEGY & $14,430.6$ & $15,928.0$ \\
EEEEY & $14,502.7$ & $15,216.4$ \\
EEEWY & $14,559.8$ & $15,330,6$ \\
EEWEY & $14,559.8$ & $15,330.6$ \\
\hline
\end{tabular}

Table S7: Y200C GFP Charge Tag Reverse Primers

\begin{tabular}{|c|c|}
\hline Y200C GFP Charge Tags & Primer \\
\hline RRRRY & AGGTCTCCTTTAATAGCGTCGCCG \\
& ACGGTGATGGTGATGGTGATGTTTGTACAG \\
\hline GGSEEEEY & $\begin{array}{c}\text { AGGTCTCCTTTAATATTCCTCTTCCTCGCTGCCA } \\
\text { CCGTGATGGTGATGGTGATGTTTGTACAGTTCA }\end{array}$ \\
\hline
\end{tabular}

Table S8: Y200C Charge Tag Forward Primer

\begin{tabular}{|c|}
\hline primer \\
\hline AGGTCTCCCATGCGTAAAGGCGAAGAGCTGTTCACTGG \\
\hline
\end{tabular}


Table S9: megaTYR Primers

\begin{tabular}{|c|c|c|}
\hline megaTYR Mutants & Forward Primer & Reverse Primer \\
\hline R209H (1) & GCGTCCACC & GCGATAATGTCG \\
& ACTGGGTAG & GGCAATCAGGTGCGAC \\
\hline R209H (2) & GTCGCACCTGATTGC & CTACCCAG \\
& CCGACATTATCGC & TGGTGGACGC \\
\hline D55K & AGGTCTCCAAGCGCA & AGGTCTCCGCTTGCT \\
& ATGCGGCGCACATGTCG & TCCAGGCGGCGTGTGG \\
\hline D55R & AGGTCTCCCGTCGCAA & AGGTCTCCGACGGCT \\
& TGCGGCGCACATGTCG & TCCAGGCGGCGTGTGG \\
\hline
\end{tabular}

Table S10: C6-Amine-DNA

\begin{tabular}{|c|}
\hline primer \\
\hline /5AmMC6/AGCAAGGGCGAGGAGCTGTTCACCG \\
\hline
\end{tabular}

\section{Chemical Synthesis}

Synthesis of Phenol-NHS

$500 \mathrm{mg}$ of 3(4-hydroxyphenyl)propanoic acid along with $589 \mathrm{mg}$ (1.7 eq.) $\quad N$-hydroxysuccinamide and $8 \mathrm{~mL}$ of THF were added to a flame dried that had previously been flushed with nitrogen gas. The flask was then placed on ice, and then $931 \mathrm{mg}$ (1.5 eq.) of DCC (dicyclohexylcarbodiimide) was slowly added to the flask. The flask was then flushed with argon gas, and the reaction was allowed to proceed on ice with gentle stirring for $2 \mathrm{~h}$. The reaction mixture was then filtered through celite and the flow through was diluted in ethyl acetate. Next, the reaction mixture was washed with saturated sodium bicarbonate solution and dried over anhydrous sodium sulfate, after which the solution was evaporated to dryness, resulting in the appearance of a white powder (Phenol-NHS Ester).

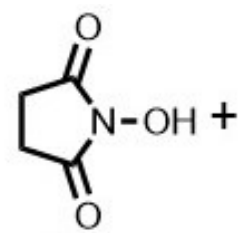

1

$1.7 \mathrm{eq}$.

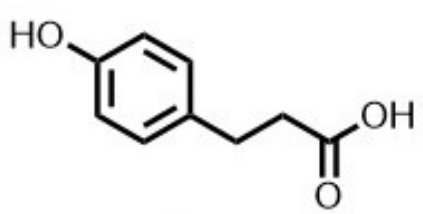

2

$1.0 \mathrm{eq}$.

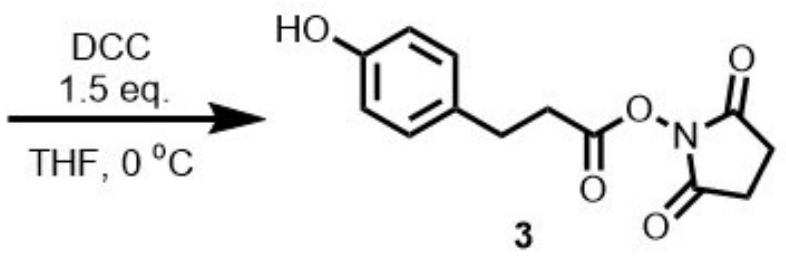

3

Scheme 1: Synthesis of Phenol-NHS Ester 
Synthesis of Phenol-DNA C6-amine DNA from IDT and Phenol NHS Ester were added to a 1:1 mixture of $100 \mathrm{mM} \mathrm{pH} 8.0$ aqueous sodium phosphate and DMF. The final concentration of DNA and phenol-NHS were $100 \mu \mathrm{M}$ and $2 \mathrm{mM}$ respectively. The reaction mixture was then placed on ice for $2 \mathrm{~h}$, after which the DNA was then desalted using a NAP ${ }^{\mathrm{TM}}-25 \mathrm{ST}$ Cytiva column from Millipore Sigma, and then lyophilized. The resulting powder was then resuspended in water to a concentration of $1 \mathrm{mM}$ and stored at $-20^{\circ} \mathrm{C}$ for later use.

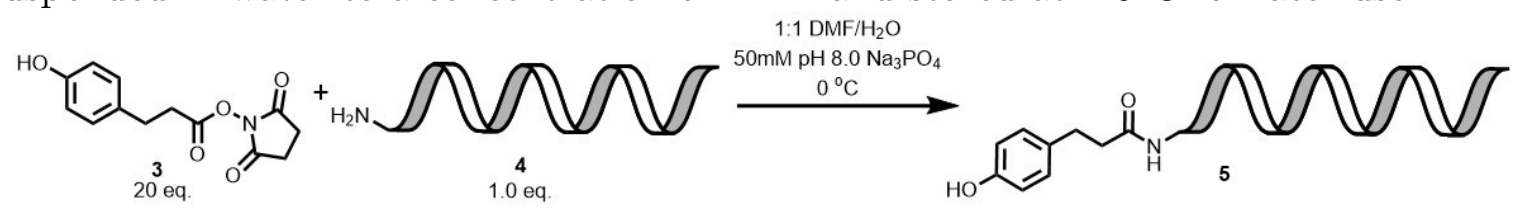

Scheme 1: Synthesis of Phenol-DNA

\section{Computational methods and electrostatic mapping:}

analysis was run on the ConSurf web server (https://consurf.tau.ac.il/) using the following parameters: multiple sequence alignment build using MAAFT, proteins from UNIREF90 database, HAMMR homolog search algorithm, HAMMR E-value: 0.1, number of HAMMR iterations: 1, Maximal \%ID: 95, Minimal \%ID: 35, choosing the top 100 sequences, conservation scores calculated using a Baysean model, and a Best Fit model of substitution for proteins. ${ }^{33-37}$ Tyrosinase crystal structures from abTYR (PDB ID: 2Y9X) and megaTYR (PDB ID: 6EI4) were uploaded into the Schrodinger Maestro software suite. A homology model for cnkTYR was generated using the Zhang lab's I-TASSER server (https://zhanglab.ccmb.med.umich.edu/I-TASSER/) using the default settings and selecting the first output. ${ }^{30-32}$ Following this, the proteins were then prepared and charges were assigned using the protein preparation wizard (PPW) tool. First, crystal structures were imported using the default settings under the import and process tab with the addition of deleting waters more than $3 \AA$ from het groups. Next, the structures were passed through H-bond Assignment tool under the refine tab using default settings. Finally, structures were passed through the restrained minimization tool with the "Hydrogens Only" box checked, using the OPLS3e force field. abTYR is a heterooctamer, and megaTYR is a monomer, and so each protein was prepared as such, 
and all metal ions other than those found in the type 3 di-nuclear copper active sites were deleted. In addition, a monomeric version of abTYR was constructed by deleting all but one subunit and subsequently put through the same PPW protocol again. Following this, single point mutants of the bacterial tyrosinase were created using the mutation tool found in the Maestro suite and all structures were passed through the second and third steps of the PPW protocol again prior to performing any calculations.

To create the surface ESP plots, the ChimaeraX electrostatic surface tool was used to generate electrostatic surfsce plots of each of the tyrosinase variants. These structures were then saved as PNG and PDB files. Next, the active site potential was calculated using the following protocol. First, a +1 lithium ion test charge was placed at a distance of 14 $\AA$ away from the active site of each enzyme variant. This distance was chosen as it is roughly equivalent to the position of the R-group of the first adjacent residue to the reactive tyrosine in a peptide in the reactive conformation, the conformation in which the tyrosine phenol moiety is placed into the enzyme active site. Then the Macromodel current energy tool was used to calculate the energies of each enzyme variant both with and without the lithium ion test charge. These calculations were performed using the OPLS3e force field with charges coming from the force field, and with water as the solvent. To calculate the ESP, the difference between the electrostatic energy contribution to the total energy for each structure were converted to an electrostatic potential difference using the following formula.

$$
V=\frac{\left(E_{\text {electrostatic }} \text { with-lithium }-E_{\text {electrostatic }_{\text {without-lithium }}}\right)\left(\frac{\mathrm{kj}}{\mathrm{mol}}\right) \times 1000}{96485.3329\left(\frac{\mathrm{C}}{\mathrm{mol}}\right)}
$$

\section{Tyrosinase-Mediated Oxidative Coupling Reactions of Proteins}

Tyrosinase mediated DNA-protein coupling:

\begin{tabular}{|c|c|c|c|}
\hline DNA $(1 \mathrm{mM})$ & GFP $(500 \mu \mathrm{M})$ & Tyrosinase $(200 \mathrm{U} / \mathrm{L})$ & Water \\
\hline $12.5 \mu \mathrm{L}$ & $5 \mu \mathrm{L}$ & $5 \mu \mathrm{L}$ & $27.5 \mu \mathrm{L}$ \\
\hline
\end{tabular}

Volumes of each stock solution indicated in the table above were added to an Eppendorf tube with the tyrosinase enzyme added last. The resulting solution was allowed to stand at 
room temperature for $1 \mathrm{~h}$ minimum before adding $5.0 \mu \mathrm{L}$ of a $100 \mathrm{mM}$ aqueous solution of tropolone. The quenched reaction was then diluted with $150 \mu \mathrm{L}$ of pH $6.550 \mathrm{mM}$ Tris-HCl buffer and analyzed using an SDS-PAGE gel.

Tyrosinase stocks and activity assay:

Agaricus bisporus tyrosinase (abTYR) was obtained from Sigma Aldrich as a lyophilized powder and stored at $-20{ }^{\circ} \mathrm{C}$ when received. Stock solutions (at $1 \mathrm{mg} / \mathrm{mL}$ ) were prepared in 50 $\mathrm{mM}$ phosphate buffer, in $15 \%$ glycerol in water, $\mathrm{pH} 6.5$, stored at $-80^{\circ} \mathrm{C}$. Bacillus megaterium tyrosinase was obtained by recombinant expression from E. coli as described above and stored as a stock solution and $-80^{\circ} \mathrm{C}$ in a similar buffer after purification. Tyrosinase aliquots were thawed on ice shortly before use and the activity of each new stock was assayed by monitoring conversion of L-Tyrosine to dopachrome via UV-Vis as described previously. ${ }^{21}$ A stability study has indicated that the activity of abTYR aliquots prepared in this manner is stable over months of storage at $-80{ }^{\circ} \mathrm{C} .{ }^{21}$

Tyrosinase peptide charge screen for subsequent TOF-LCMS analysis:

\begin{tabular}{llllll}
\hline $\mathrm{Na}_{2} \mathrm{HPO}_{4} \mathrm{pH} 6.5$ & & \multicolumn{3}{l}{ Protein Nucleophile } \\
\hline $\mathrm{i}(\mathrm{mM})$ & $\mathrm{f}(\mathrm{mM})$ & vol $(\mu \mathrm{L})$ & $\mathrm{i}(\mu \mathrm{M})$ & $\mathrm{f}(\mu \mathrm{M})$ & vol $(\mu \mathrm{L})$ \\
\hline 50 & 10 & 10.0 & 500 & 50.0 & 5 \\
\hline
\end{tabular}

\begin{tabular}{llllllll}
\hline \multicolumn{3}{l}{ Peptide $(\mathrm{mg} / \mathrm{mL})$} & \multicolumn{2}{l}{ Tyrosinase } & & $\mathrm{H}_{2} \mathrm{O}$ & Total Vol \\
\hline $\mathrm{i}(\mu \mathrm{M})$ & $\mathrm{f}(\mu \mathrm{M})$ & vol $(\mu \mathrm{L})$ & $\mathrm{i}(\mathrm{U} / \mathrm{L})$ & $\mathrm{f}(\mathrm{U} / \mathrm{L})$ & $\mathrm{Vol}(\mu \mathrm{L})$ & $(\mu \mathrm{L})$ & $(\mu \mathrm{L})$ \\
\hline 1000 & 250 & 12.5 & 120 & 12.0 & 5.00 & 17.5 & 50.0 \\
\hline
\end{tabular}

Volumes of each stock solution indicated in the table above were added to an Eppendorf tube with the tyrosinase enzyme added last. The resulting solution was allowed to stand at room temperature for 30 min before adding $5.0 \mu \mathrm{L}$ of a $100 \mathrm{mM}$ aqueous solution of tropolone. The quenched reaction was then diluted with $150 \mu \mathrm{L}$ of pH $6.550 \mathrm{mM}$ Tris-HCl buffer and submitted to TOF-LCMS analysis. This standard procedure was followed unless indicated otherwise.

Maleimide Tyrosinase biotin GFP dimer formation 
Y200C-EEEEY GFP was capped with maleimide biotin following a previously reported protocol. ${ }^{23}$ The resulting solution was then spin-concentrated 6 times using a $50 \mathrm{kDa}$ MWCO spin filter from Milipore to remove excess maleimide biotin. The retained sample was then combined at $10 \mu \mathrm{M}$ with $100 \mu \mathrm{M}$ of Y200C sfGFP with D55R megaTYR (12 U/L equivalent) for 45 min before quenching and spin concentration using a $50 \mathrm{kDa}$ MWCO spin filter.

\section{Tyrosinase-mediated biotin protein dimer formation}

Tyrosinase aliquots were thawed on ice shortly before use and diluted to a 10x stock solution. In the first reaction $10 \mu \mathrm{M}$ Y200C GFP-GGSEEEEY was combined with 100 $\mu \mathrm{M}$ tyrosine biotin and $200 \mathrm{nM}$ abTYR for $40 \mathrm{~min}$ at RT before quenching with tropolone. Solution was then spin-concentrated 6 times using a 50 kDa MWCO spin filter from Milipore to remove excess luciferase. The retained sample was then combined at $10 \mu \mathrm{M}$ with $100 \mu \mathrm{M}$ of Y200C sfGFP with D55R megaTYR (12 U/L equivalent) for 45 min before quenching and spin concentration using a $50 \mathrm{kDa}$ MWCO spin filter.

\section{Tyrosinase-mediated protein trimer formation}

Tyrosinase aliquots were thawed on ice shortly before use and diluted to a 10x stock solution. In the first reaction $10 \mu \mathrm{M}$ Y200C GFP-GGSEEEEY was combined with 100 pM MYGGS-nanoluciferase and $200 \mathrm{nM}$ abTYR for $40 \mathrm{~min}$ at RT before quenching with tropolone. Solution was then spin-concentrated 6 times using a $50 \mathrm{kDa}$ MWCO spin filter from Milipore to remove excess luciferase. The retained sample was then combined at $10 \mu \mathrm{M}$ with $100 \mu \mathrm{M}$ of Y200C sfGFP with D55R megaTYR (12 U/L equivalent) for 45 min before quenching and spin concentration using a $50 \mathrm{kDa}$ MWCO spin filter.

\section{References}

(1) Zeng, Y.-S.; Gao, R.-C.; Wu, T.-W.; Cho, C.; Tan, K.-T. Fluorescent probe encapsulated in SNAP-Tag protein cavity to eliminate nonspecific fluorescence and increase detection sensitivity. Bioconjugate chemistry 2016, 27, 1872-1879. 
(2) Gao, J.; Hori, Y.; Takeuchi, O.; Kikuchi, K. Live-Cell Imaging of Protein Degradation Utilizing Designed Protein-Tag Mutant and Fluorescent Probe with Turn-Off Switch. Bioconjugate Chemistry 2019, 31, 577-583.

(3) Phillips, G. D. L.; Li, G.; Dugger, D. L.; Crocker, L. M.; Parsons, K. L.; Mai, E.; Blättler, W. A.; Lambert, J. M.; Chari, R. V.; Lutz, R. J., et al. Targeting HER2positive breast cancer with trastuzumab-DM1, an antibody-cytotoxic drug conjugate. Cancer research 2008, 68, 9280-9290.

(4) Steen Redeker, E.; Ta, D. T.; Cortens, D.; Billen, B.; Guedens, W.; Adriaensens, P. Protein engineering for directed immobilization. Bioconjugate chemistry 2013, 24, 17611777.

(5) Koo, B.; Dolan, N. S.; Wucherer, K.; Munch, H. K.; Francis, M. B. Site-Selective Protein Immobilization on Polymeric Supports through N-Terminal Imidazolidinone Formation. Biomacromolecules 2019, 20, 3933-3939.

(6) Chen, L.; Cohen, J.; Song, X.; Zhao, A.; Ye, Z.; Feulner, C. J.; Doonan, P.; Somers, W.; Lin, L.; Chen, P. R. Improved variants of SrtA for site-specific conjugation on antibodies and proteins with high efficiency. Scientific reports 2016, 6, 1-12.

(7) Khatwani, S. L.; Kang, J. S.; Mullen, D. G.; Hast, M. A.; Beese, L. S.; Distefano, M. D.; Taton, T. A. Covalent protein-oligonucleotide conjugates by copper-free click reaction. Bioorganic \&f medicinal chemistry 2012, 20, 4532-4539.

(8) Horisawa, K. Specific and quantitative labeling of biomolecules using click chemistry. Frontiers in physiology 2014, 5, 457.

(9) Ravasco, J. M.; Faustino, H.; Trindade, A.; Gois, P. M. Bioconjugation with maleimides: A useful tool for chemical biology. Chemistry-A European Journal 2019, 25, 43-59. 
(10) Guimaraes, C. P.; Witte, M. D.; Theile, C. S.; Bozkurt, G.; Kundrat, L.; Blom, A. E.; Ploegh, H. L. Site-specific C-terminal and internal loop labeling of proteins using sortase-mediated reactions. Nature protocols 2013, 8, 1787.

(11) Nguyen, G. K.; Kam, A.; Loo, S.; Jansson, A. E.; Pan, L. X.; Tam, J. P. Butelase 1: a versatile ligase for peptide and protein macrocyclization. Journal of the American Chemical Society 2015, 137, 15398-15401.

(12) Nguyen, G. K.; Qiu, Y.; Cao, Y.; Hemu, X.; Liu, C.-F.; Tam, J. P. Butelase-mediated cyclization and ligation of peptides and proteins. Nature protocols 2016, 11, 1977-1988.

(13) Blanden, M. J.; Suazo, K. F.; Hildebrandt, E. R.; Hardgrove, D. S.; Patel, M.; Saunders, W. P.; Distefano, M. D.; Schmidt, W. K.; Hougland, J. L. Efficient farnesylation of an extended C-terminal C (x) 3X sequence motif expands the scope of the prenylated proteome. Journal of Biological Chemistry 2018, 293, 2770-2785.

(14) Zakeri, B.; Fierer, J. O.; Celik, E.; Chittock, E. C.; Schwarz-Linek, U.; Moy, V. T.; Howarth, M. Peptide tag forming a rapid covalent bond to a protein, through engineering a bacterial adhesin. Proceedings of the National Academy of Sciences 2012, 109, E690-E697.

(15) Inlow, J. K. Homology models of four Agaricus bisporus tyrosinases. International journal of biological macromolecules 2012, 50, 283-293.

(16) Iozumi, K.; Hoganson, G. E.; Pennella, R.; Everett, M. A.; Fuller, B. B. Role of tyrosinase as the determinant of pigmentation in cultured human melanocytes. Journal of Investigative Dermatology 1993, 100, 806-811.

(17) Kanteev, M.; Goldfeder, M.; Chojnacki, M.; Adir, N.; Fishman, A. The mechanism of copper uptake by tyrosinase from Bacillus megaterium. JBIC Journal of Biological Inorganic Chemistry 2013, 18, 895-903. 
(18) Bijelic, A.; Pretzler, M.; Molitor, C.; Zekiri, F.; Rompel, A. The structure of a plant tyrosinase from walnut leaves reveals the importance of "Substrate-Guiding Residues" for enzymatic specificity. Angewandte Chemie International Edition 2015, 54, 1467714680.

(19) Kim, H.; Yeon, Y. J.; Choi, Y. R.; Song, W.; Pack, S. P.; Choi, Y. S. A cold-adapted tyrosinase with an abnormally high monophenolase/diphenolase activity ratio originating from the marine archaeon Candidatus Nitrosopumilus koreensis. Biotechnology letters 2016, 38, 1535-1542.

(20) Bruins, J. J.; Westphal, A. H.; Albada, B.; Wagner, K.; Bartels, L.; Spits, H.; van Berkel, W. J.; van Delft, F. L. Inducible, site-specific protein labeling by tyrosine oxidation-strain-promoted $(4+2)$ cycloaddition. Bioconjugate chemistry 2017, 28, 1189-1193.

(21) Maza, J. C.; Bader, V. D. L.; Xiao, L.; Marmelstein, A. M.; Brauer, D. D.; ElSohly, A. M.; Smith, M. J.; Krska, S. W.; Parish, C. A.; Francis, M. B. Enzymatic Modification of N-Terminal Proline Residues Using Phenol Derivatives. Journal of the American Chemical Society 2019, 141, 3885-3892.

(22) Marmelstein, A. M.; Lobba, M. J.; Mogilevsky, C. S.; Maza, J. C.; Brauer, D. D.; Francis, M. B. Tyrosinase-Mediated Oxidative Coupling of Tyrosine Tags on Peptides and Proteins. Journal of the American Chemical Society 2020, 142, 5078-5086.

(23) Lobba, M. J.; Fellmann, C.; Marmelstein, A. M.; Maza, J. C.; Kissman, E. N.; Robinson, S. A.; Staahl, B. T.; Urnes, C.; Lew, R. J.; Mogilevsky, C. S., et al. Site-Specific Bioconjugation through Enzyme-Catalyzed Tyrosine-Cysteine Bond Formation. ACS central science 2020, 6, 1564-1571.

(24) Donaldson, J. M.; Zer, C.; Avery, K. N.; Bzymek, K. P.; Horne, D. A.; Williams, J. C. Identification and grafting of a unique peptide-binding site in the Fab framework of 
monoclonal antibodies. Proceedings of the National Academy of Sciences 2013, 110, $17456-17461$.

(25) Ismaya, W. T.; Rozeboom, H. J.; Weijn, A.; Mes, J. J.; Fusetti, F.; Wichers, H. J.; Dijkstra, B. W. Crystal structure of Agaricus bisporus mushroom tyrosinase: identity of the tetramer subunits and interaction with tropolone. Biochemistry 2011, 50, 54775486.

(26) Do, H.; Kang, E.; Yang, B.; Cha, H. J.; Choi, Y. S. A tyrosinase, mTyr-CNK, that is functionally available as a monophenol monooxygenase. Scientific reports 2017, 7, 1-8.

(27) Ben-Yosef, V. S.; Sendovski, M.; Fishman, A. Directed evolution of tyrosinase for enhanced monophenolase/diphenolase activity ratio. Enzyme and Microbial Technology 2010, 47, 372-376.

(28) Goldfeder, M.; Kanteev, M.; Adir, N.; Fishman, A. Influencing the monophenolase/diphenolase activity ratio in tyrosinase. Biochimica et Biophysica Acta (BBA)Proteins and Proteomics 2013, 1834, 629-633.

(29) Deri, B.; Kanteev, M.; Goldfeder, M.; Lecina, D.; Guallar, V.; Adir, N.; Fishman, A. The unravelling of the complex pattern of tyrosinase inhibition. Scientific reports $\mathbf{2 0 1 6}$, 6,34993 .

(30) Roy, A.; Kucukural, A.; Zhang, Y. I-TASSER: a unified platform for automated protein structure and function prediction. Nature protocols 2010, 5, 725-738.

(31) Zhang, Y. I-TASSER server for protein 3D structure prediction. BMC bioinformatics 2008, 9, 1-8.

(32) Yang, J.; Yan, R.; Roy, A.; Xu, D.; Poisson, J.; Zhang, Y. The I-TASSER Suite: protein structure and function prediction. Nature methods 2015, 12, 7-8. 
(33) Glaser, F.; Pupko, T.; Paz, I.; Bell, R. E.; Bechor-Shental, D.; Martz, E.; Ben-Tal, N. ConSurf: identification of functional regions in proteins by surface-mapping of phylogenetic information. Bioinformatics (Oxford, England) 2003, 19, 163-164.

(34) Landau, M.; Mayrose, I.; Rosenberg, Y.; Glaser, F.; Martz, E.; Pupko, T.; Ben-Tal, N. ConSurf 2005: the projection of evolutionary conservation scores of residues on protein structures. Nucleic Acids Research 2005, 33, W299-302.

(35) Celniker, G.; Nimrod, G.; Ashkenazy, H.; Glaser, F.; Martz, E.; Mayrose, I.; Pupko, T.; Ben-Tal, N. ConSurf: Using Evolutionary Data to Raise Testable Hypotheses about Protein Function. Israel Journal of Chemistry 2013, 53, 199-206.

(36) Ashkenazy, H.; Erez, E.; Martz, E.; Pupko, T.; Ben-Tal, N. ConSurf 2010: calculating evolutionary conservation in sequence and structure of proteins and nucleic acids. Nucleic Acids Research 2010, 38, W529-W533.

(37) Ashkenazy, H.; Abadi, S.; Martz, E.; Chay, O.; Mayrose, I.; Pupko, T.; Ben-Tal, N. ConSurf 2016: an improved methodology to estimate and visualize evolutionary conservation in macromolecules. Nucleic Acids Research 2016, 44, W344-W350.

(38) Carrico, Z. M.; Romanini, D. W.; Mehl, R. A.; Francis, M. B. Oxidative coupling of peptides to a virus capsid containing unnatural amino acids. Chemical communications 2008, 1205-1207.

(39) Tong, G. J.; Hsiao, S. C.; Carrico, Z. M.; Francis, M. B. Viral capsid DNA aptamer conjugates as multivalent cell-targeting vehicles. Journal of the American Chemical Society 2009, 131, 11174-11178.

(40) Mehl, R. A.; Anderson, J. C.; Santoro, S. W.; Wang, L.; Martin, A. B.; King, D. S.; Horn, D. M.; Schultz, P. G. Generation of a bacterium with a 21 amino acid genetic code. Journal of the American Chemical Society 2003, 125, 935-939. 
(41) Engler, C.; Kandzia, R.; Marillonnet, S. A one pot, one step, precision cloning method with high throughput capability. PloS one 2008, 3, e3647. 
${ }_{648}$ Graphical TOC Entry

Charge Directed Sequential Activation of Tyrosines

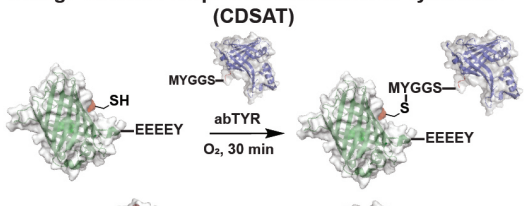

HS

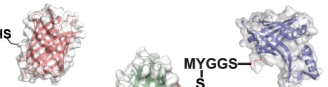

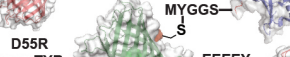

$\underset{\mathrm{O}_{2,30 \mathrm{~min}}}{\mathrm{megaTYR}}$ yfige 